\title{
Evaluation of the Dynamic Behavior, Elastic Properties, and in Vitro Bioactivity of Some Borophosphosilicate Glasses for Orthopedic Applications
}

\author{
Waheed S. Abushanab \\ King Abdulaziz University \\ Essam B. Moustafa \\ King Abdulaziz University (KAU) \\ Rasha Youness ( $\nabla$ rhakamnrc@gmail.com ) \\ National Research Centre, El Buhouth St
}

\section{Research Article}

Keywords: Finite element model, Dynamic behavior, Buckling analysis, Stress analysis, In vitro bioactivity, Borophosphosilicate glass

Posted Date: September 11th, 2021

DOl: https://doi.org/10.21203/rs.3.rs-883520/v1

License: (c) (i) This work is licensed under a Creative Commons Attribution 4.0 International License.

Read Full License

Version of Record: A version of this preprint was published at Journal of Non-Crystalline Solids on June 1st, 2022. See the published version at https://doi.org/10.1016/j.jnoncrysol.2022.121539. 


\section{Abstract}

The present work employed the finite element model (FEM) to predict the influence of successive increases in borate $\left(\mathrm{B}_{2} \mathrm{O}_{3}\right)$ contents, from 0 to $25 \mathrm{~mol} \%$, on both the mechanical properties and dynamic behavior. By feeding the isotropic elasticity characteristics of the phosphosilicate glass to the model, such as Young's modulus, density, and maximum compressive stress of the produced glass samples to fit the aim of their clinical use. The effect of successive addition of $\mathrm{B}_{2} \mathrm{O}_{3}$ on the in vitro bioactivity of the examined glasses in addition to examined after being dipped in simulated body fluid (SBF) at different times. Moreover, tracking the formation of hydroxyapatite (HA)-like layers on their surfaces using X-ray diffraction technique (XRD) technique and scanning electron microscopy (SEM). The results obtained indicated that increasing $\mathrm{B}_{2} \mathrm{O}_{3}$ content to $25 \%$ was responsible for improving the deflect resistance by $39 \%$. On the other hand, neither shear stress nor principles stress was affected by this increase in $\mathrm{B}_{2} \mathrm{O}_{3}$ content. Moreover, the gradual increases in $\mathrm{B}_{2} \mathrm{O}_{3}$ contents were very helpful in improving the bioactivity of the samples. From these promising results, the prepared glasses can be successfully used in bone replacement applications.

\section{Introduction}

It is well-known that bone tissue can repair itself when damaged. Unfortunately, if this damage is significant, the bone tissue will not be able to heal itself without outside medical help [1]. Based on this fact, various biomaterials have been developed in the last fifty years, thanks to the extensive efforts of scientists to help bone repair and bone regeneration [2].

In tight correlation with medical needs, bioactive materials have received great attention for use in different biomedical applications due to their promising characteristics. Accordingly, it can be considered that bioceramics and their composites are favorable for these applications $[3,4]$. In this context, bioactive glass (BG) is one of the most promising candidates for use as a bone replacement material due to its great ability to form a hydroxyapatite $(\mathrm{HA})$ layer when infused into the human body, along with its excellent biocompatibility [5-7]. It is worth noting that these amazing biomaterials were discovered due to the tireless efforts of Professor L.L. Hench at the University of Florida in 1969 [8]. In addition, during the formation of the HA layer, the ions released from BG are very beneficial for inducing the proliferation and differentiation of osteoblasts [9]. Knowing that the properties of the prepared BGs are strongly related to their chemical composition, one can expect that researchers are still motivated to continue searching for glass compositions that have many unique and attractive properties for use in bone substitute applications $[3,10,11]$.

Phosphate-based glasses (PBGs) have many attractive characteristics such as high solubility rate, good bioactivity, and excellent biocompatibility due to their similarity to the human bones [12]. Unfortunately, their poor chemical durability coupled with low mechanical properties are the most constraints to their use in biomedical applications [13]. Therefore, there is an urgent need to improve their properties above. To counteract these limitations, the addition of silicon dioxide $\left(\mathrm{SiO}_{2}\right)$ as a glass former is beneficial 
because it has suitable mechanical properties and good biocompatibility and biological significance in bone formation and calcification [11, 14-16].

Boron is a natural element found in several organs within the human body, such as bone, hair, and nails, besides its important role in stimulating some essential metabolic enzymes [17, 18]. Boron also enhances RNA synthesis in fibroblast cells and stimulates bone formation. It is considered an effective agent for bone tissue engineering applications $[19,20]$. Moreover, boron can be added to bioactive silicate glasses to enhance bioactivity [21-23]. In addition, boron-containing glasses are characterized by low chemical stability, and therefore, they can be converted to HA faster and more completely when dipped in simulated body fluid (SBF) [24-26].

Over the past few decades, many articles have studied the bioactivity of borophosphate [27-29], borosilicate [30-32], and phosphosilicate glasses and glass-ceramics [33-35]. However, the bioactivity of borophosphosilicate glasses with a detailed prediction of the behavior of these glasses when implanted in the human body under body weight, investigate and explore the effect of increased loads and their relationship to the deflection that occurs in the structure of the samples and whether the bioactive glass samples will undergo yield or fracture has not been previously studied.

\section{Methodology}

\subsection{Glass preparation}

Melt quenched $25 \mathrm{Na}_{2} \mathrm{O}-20 \mathrm{CaO}-10 \mathrm{SiO}_{2}-(45-\mathrm{x}) \mathrm{P}_{2} \mathrm{O}_{5}-\mathrm{xB}_{2} \mathrm{O}_{3}$ glasses with $\mathrm{x}=0,10,20$, and $25 \mathrm{~mol} \%$ have been prepared from starting materials of analytical reagent grade. Silicon oxide $\left(\mathrm{SiO}_{2}\right)$, sodium carbonate $\left(\mathrm{Na}_{2} \mathrm{CO}_{3}\right)$, calcium carbonate $\left(\mathrm{CaCO}_{3}\right)$, orthoboric acid $\left(\mathrm{H}_{3} \mathrm{BO}_{3}\right)$, and ammonium dihydrogen phosphate $\left(\mathrm{NH}_{4} \mathrm{H}_{2} \mathrm{PO}_{4}\right)$ powders were thoroughly mixed in the appropriate quantities and then ground in an agate mortar. The weighed well-mixed batches were melted in a porcelain crucible in an electric furnace at 1100 ${ }^{\circ} \mathrm{C}$ for $3 \mathrm{~h}$. The molten liquid was occasionally stirred to ensure homogeneous mixing of all constituents and to obtain bubble-free samples. The glass, formed by quenching the melt on a stainless-steel mold, was immediately transferred to another muffle furnace for annealing at about $350^{\circ} \mathrm{C}$ for $1 \mathrm{~h}$. Then, the muffle was switched off, and the temperature decreased to room temperature with a rate of $20^{\circ} \mathrm{C} / \mathrm{h}$. The nominal compositions of the prepared glasses, together with their abbreviations, are given in Table 1.

\subsection{Structural characterization of glasses}

In this study, Fourier transform infrared (FTIR; Vertex 80, Bruker, Germany) spectroscopy was carried out to examine the molecular structure of as-prepared glasses. The FTIR absorption spectra of the tested samples were immediately collected by an attenuated total reflection (ATR) unit, at room temperature, in the wavenumber range $4000-400 \mathrm{~cm}-1,60$ scans with a $4 \mathrm{~cm}^{-1}$. Moreover, X-ray diffraction technique (XRD; Philips PW 1373; X-ray powder diffractometer with CuK-Ni filtered radiation) was employed in this work to ensure the amorphous structure of the glass samples and follow up the formation of HA-like layer 
on their surfaces after their soaking in simulated body fluid (SBF) solution for different time periods; namely 3,7 and 10 days.

\subsection{In vitro bioactivity (bone-bonding) assessment of glass samples}

In vitro bioactivity was assessed by soaking the glass samples in simulated body fluid (SBF) prepared according to the recipe described by Kokubo et al. [36,37]. The glasses were ground to grains and sieved, keeping the ratio of specimen mass to the volume of SBF solution $=0.01 \mathrm{~g} / \mathrm{mL}$ to achieve an excess SBF volume surrounding the samples [38]. Then, they were subjected to XRD technique to follow the formation of the HA layer. Moreover, cubic slabs of glass samples with dimensions of $5 \times 5 \times 5 \mathrm{~mm}^{3}$ were prepared for examination by scanning electron microscopy (SEM; Quanta FEG250; with an accelerating voltage of $30 \mathrm{kV}$ and magnification of $\times 10$ up to $\times 300,000)$ after soaking in SBF solution for 3,7 and 10 days.

\subsection{Density measurement}

The density $(\rho)$ of each glass sample was measured at room temperature using the Archimedes method with water as the immersion liquid.

\subsection{Mechanical properties}

As mentioned before in our recent articles [39,40], all glass samples' microhardness and compressive strength were measured according to ASTM: B933-09 and ASTM E9, respectively. On the other hand, the ultrasonic wave velocities (longitudinal and shear) propagated in the samples were obtained at room temperature, using pulse-echo technique MATEC Model MBS8000 DSP (ultrasonic digital signal processing) system with $5 \mathrm{MHz}$ resonating as described in Refs. [41-43].

Longitudinal $\left(\mathrm{V}^{2} \mathrm{~L}\right)$ and shear $\left(\mathrm{V}_{\mathrm{S}}{ }_{\mathrm{S}}\right)$ ultrasonic velocities can be used to determine the values of Lame's constants, i.e., $\lambda$ and $\mu$ as the followings:

$$
\begin{aligned}
\lambda & =\rho\left(V_{L}^{2}-2 V_{S}^{2}\right) \\
\mu & =\rho V_{S}^{2} \\
L & =\lambda+2 \mu \\
G & =\mu \\
E & =\mu \frac{3 \lambda+2 \mu}{\lambda+\mu} \\
B & =\lambda+\frac{2}{3} \mu \\
ט & =\frac{\lambda}{2(\lambda+\mu)}
\end{aligned}
$$

\section{Results And Discussion}




\subsection{Structural characterization of glasses using FTIR spectroscopy}

In contrast to the XRD technique, FTIR spectroscopy is able to record the functional groups of glasses in the mid-IR region in a precise manner [44]. Based on this concept, FTIR spectroscopy was carried out to examine the molecular structure of the prepared glasses, as shown in Fig. 1. Before assigning the spectra obtained from the glass samples, it is preferable to briefly mention some facts about the chemistry of phosphate bioactive glass (PBG) as follows:

As discussed in Refs. $[29,45]$, in the absence of modifier oxides, PBG is mainly composed of $\mathrm{PO}_{4}{ }^{3-}$ tetrahedral units in chain/ring structures, having much non-bridging oxygen (NBO) atoms. Therefore, these glasses are characterized by low chemical durability along with low melting temperatures. However, in the presence of modifier oxides (MO), the phosphate network is depolymerized as a result of the replacement of some of the $\mathrm{P}-\mathrm{O}-\mathrm{P}$ links with $-\mathrm{P}-\mathrm{O}-\mathrm{M}$ - ones leading to a considerable change in the glass structure from $Q^{3}$ units to tetrahedral chains in the metaphosphate ( $Q^{2}$ units), pyrophosphate ( $Q^{1}$ units) and orthophosphate ( $Q^{0}$ anions) bearing in mind that this conversion depends on the type and contents of modifying oxides. On the other hand, borate consists of three boron-oxygen triangles forming boroxol rings/groups $\left(\mathrm{B}_{3} \mathrm{O}_{6}\right)$. However, this coordination is changed from triangular to tetrahedral after adding alkali oxide $(\mathrm{CaO})$ or alkaline earth oxide $\left(\mathrm{Na}_{2} \mathrm{O}\right)$. The FTIR absorption bands of phosphate groups can be classified into three fundamental regions; namely region of $1400-1150 \mathrm{~cm}^{-1}$ that represents the vibrations of non-bridging $\mathrm{PO}_{2}$ groups, region of $1150-900 \mathrm{~cm}^{-1}$ that symbolizes the vibrations of $\mathrm{P}-\mathrm{O}$ and $\mathrm{PO}_{3}$ groups and region of $900-700 \mathrm{~cm}^{-1}$ that expresses the vibrations of bridging $\mathrm{P}-\mathrm{O}-\mathrm{P}$ groups. However, borate groups exhibit three spectral regions at 800-600, 1500-1200, and 1200-850 $\mathrm{cm}^{-1}$, which emerge from the $\mathrm{B}-\mathrm{O}$ stretching mode of the borate part, $\mathrm{B}-\mathrm{O}$ stretching mode of $\mathrm{BO}_{3}$ and $\mathrm{BO}_{4}$ units, respectively [23]. Importantly, the most characteristic region for bioactive silicate glasses falls in the spectral region 1050-850 $\mathrm{cm}^{-1}$. Based upon the abovementioned regions, the present spectra can be assigned according to the literature $[21,23,46-49]$ as follows:

- B-O stretching vibrations of the triangular $\left(\mathrm{BO}_{3}, \mathrm{BO}_{2} \mathrm{O}^{-}\right)$units can be confirmed by the weak band located at $1250 \mathrm{~cm}^{-1}$, considering that the increase in $\mathrm{B}_{2} \mathrm{O}_{3}$ contents leads to a considerable increase in its intensity until it reaches medium one.

- A single sharp, strong band can indicate the symmetric stretching mode of the $P=0$ bond at $1200 \mathrm{~cm}^{-}$ ${ }^{1}$. As expected, an increase in $\mathrm{B}_{2} \mathrm{O}_{3}$ contents causes its intensity to decrease until it reaches a medium intensity.

- Intense broadband located near $1045 \mathrm{~cm}^{-1}$ can be attributed to the superposition of symmetric stretching mode of $\mathrm{Q}^{2}$ units, symmetric stretching mode of $\mathrm{O}-\mathrm{P}-\mathrm{O}$ bonds, asymmetric stretching mode of $\mathrm{Si}-\mathrm{O}-\mathrm{Si}$ vibrations, and asymmetric stretching vibration of tetrahedral borate units.

- A weak band at $970 \mathrm{~cm}^{-1}$ can be ascribed to symmetric stretching vibrations of $\mathrm{Si}-\mathrm{O}-\mathrm{Si}$ and $\mathrm{B}-\mathrm{O}$ bond of tetrahedral $\mathrm{BO}_{4}$ groups. Of note, by increasing $\mathrm{B}_{2} \mathrm{O}_{3}$ content in the glass composition, the 
intensity of this band increases.

- The asymmetric stretching mode of the P-O-P bonds accompanying the formation of $\mathrm{Q}^{2}$ chains can be represented by having two shoulders at 925 and $820 \mathrm{~cm}^{-1}$. On the other hand, a medium band at $765 \mathrm{~cm}^{-1}$ can be assigned to the symmetric stretching vibration of $\mathrm{P}-\mathrm{O}-\mathrm{P}$ and the bending/deformation modes of different borate units. Moreover, the shoulder at $925 \mathrm{~cm}^{-1}$ represents an asymmetric stretching mode of the $\mathrm{Si}-\mathrm{O}$ bond.

- Broadband at $470 \mathrm{~cm}^{-1}$ can be ascribed to the overlapping of bending vibrations of the $\mathrm{B}-\mathrm{O}-\mathrm{B}$ bonds, $\mathrm{Q}^{1}$ units of phosphate groups, and $\mathrm{Si}-\mathrm{O}$ bonds. It is reasonable to expect that the intensity of this band considerably increases due to the increased contents of $\mathrm{B}_{2} \mathrm{O}_{3}$, which also results in the conversion of some $\mathrm{Q}^{2}$ phosphate units to $\mathrm{Q}^{1}$ ones.

- Bending vibrations of $\mathrm{P}-\mathrm{O}-\mathrm{P}$ and $\mathrm{Si}-\mathrm{O}$ bonds can be indicated by the presence of a medium band found at $465 \mathrm{~cm}^{-1}$.

\subsection{Evaluation of bioactivity behavior (bone-bonding) of prepared glass samples}

\subsubsection{XRD analysis}

In this work, glass samples were subjected to XRD technique before and after dipping in SBF solution for different time periods, i.e., 3,7 , and 10 days to ensure their amorphous structure as well as the formation of an apatite-like layer on their surfaces as shown in Fig. 2 (a-d). It is suggested from Fig. 2a that all samples have an amorphous structure as indicated by the presence of broadband at $2 \theta=20-30^{\circ}$. This observation is extremely important as it refers to the correct preparation procedures for glass samples [50]. On the other hand, the soaked samples in SBF solution exhibit crystalline HA layer, which is easily identified according to (JCPDS No. 19-0272), bearing in mind that the bioactivity of samples are positively affected by increasing soaking time as well as $\mathrm{B}_{2} \mathrm{O}_{3}$ contents where the best bioactivity is observed for S4 sample after its soaking in SBF solution for 10 days. The most likely explanation for the enhancement of the bioactivity of the examined samples with increasing incubation time is that increasing the soaking time leads to an increase of $\mathrm{Ca}^{2+}$ and $\mathrm{PO}_{4}{ }^{3-}$ ions on their surfaces [46]. It is generally considered that the existence of $\mathrm{Na}^{+}$and $\mathrm{Ca}^{2+}$ in the prepared glasses act as modifiers for the network where they trigger the formation of non-bridging oxygen (NBO) atoms which in turn increase the degradation of glasses. In this regard, it is very meaningful to discuss the famous mechanism proposed by Hench et al. [8], which described the formation of an HA-layer on silicate-based glass surfaces, which usually occurs through specific steps. These steps begin by exchanging $\mathrm{Na}+\mathrm{ions}$, from the soaked glass sample, with $\mathrm{H}+$ ones, from SBF solution, causing breakage in the glass network and forming $\mathrm{Si}-\mathrm{OH}$ groups at the glass/SBF interface. Then, these groups are polycondensed, leading to the formation of a silica gel layer on the glass sample surface. On the opposite side, $\mathrm{OH}^{-}$groups work as effective nucleation sites for the precipitation as well as crystallization of HA layer. These stages are finalized by the formation of sufficient $\mathrm{HA}$ nuclei and immigration of $\mathrm{Ca}^{2+}$ and $\mathrm{PO}_{4}{ }^{3-}$ groups from SBF solution and glass matrix producing amorphous calcium phosphate (Ca-P) film. Consequently, significant growth for 
$\mathrm{HA}$ layer is achieved. Since the current glass system has a low $\mathrm{SiO}_{2}$ content while being rich in $\mathrm{P} 2 \mathrm{O} 5$ and B2O3, we should expect other mechanisms for the bioactivity of the prepared glass samples.

As discussed in Ref. [51], the affinity of $\mathrm{Na}^{+}$and $\mathrm{Ca}^{2+}$ ions to the phosphate network is much higher than the silicate network. Therefore, the latter network suffers from polymerization, causing the formation of $\mathrm{Si}-\mathrm{O}-\mathrm{Si}$ and $\mathrm{Si}-\mathrm{O}-\mathrm{P}$ linkages. The latter linkages are responsible for reducing the bioactivity of glass. Fortunately, the present glass system possesses a lower contribution of $\mathrm{SiO} 2$ than that of $\mathrm{P}_{2} \mathrm{O}_{5}$; the bioactivity of the examined S1 sample is not greatly affected by Si-O-P groups. Increasing the content of $\mathrm{B}_{2} \mathrm{O}_{3}$ contributes to the improvement of bioactivity considerably. One possible reason for this positive result is that when $\mathrm{B}_{2} \mathrm{O}_{3}$ increases, at the expense of $\mathrm{P}_{2} \mathrm{O}_{5}$, it helps to reach a non-stoichiometric ratio of Ca:P. Another reason is the high solubility of $\mathrm{B}_{2} \mathrm{O}_{3}$, which contributes to breaking the glass network and the formation of $\mathrm{B}-\mathrm{OH}$ bonds that act as a catalyst for bioactivity [52]. Noteworthy, the aforementioned stages greatly contribute to precipitation of calcium phosphate (Ca-P) layer on the glasses surfaces and subsequently turn into a crystalline layer, i.e., HA. Importantly, the formation of HA layer can be clearly understood with the help of the following Eqn. [47,48]:

$10 \mathrm{Ca}^{2+}+6 \mathrm{PO}_{4}{ }^{3-}+2 \mathrm{OH}^{-} \rightarrow \mathrm{Ca}_{10}\left(\mathrm{PO}_{4}\right)_{6}(\mathrm{OH})_{2}$

It cannot be denied that HA nuclei's heterogeneous nucleation can be achieved by the super-saturation limit elevation above the critical level. Notably, the increase of released $\mathrm{Na}^{+}$ions is responsible for such an increase in the super-saturation level of the soaking solution in connection to HA. Then, enlargement of $\mathrm{HA}$ nuclei occurs due to the consumption of $\mathrm{Ca}^{2+}, \mathrm{PO}_{4}{ }^{3-}$ and $\mathrm{OH}^{-}$ions from the $\mathrm{SBF}$ [53].

\subsubsection{SEM analysis}

In order to follow the formation of HA layer on the surface of S4 sample after soaking in SBF solution for 3,7 , and 10 days, SEM was used in this work, as shown in Fig. 3 (a-c), respectively. It should be noted that the selection of this sample for SEM examination is based on the XRD results obtained, which show that the best bioactivity characterized $\mathrm{S} 4$ sample among all tested samples as a result of containing the highest percentage of $\mathrm{B}_{2} \mathrm{O}_{3}$. It is possible to see from Fig. 3a the formation of a large number of $\mathrm{HA}$ crystals seen individually without the formation of the characteristic shape of the layer reflecting that the poor crystallization of these crystals. However, as can be seen from Fig. 3b, the prolonged soaking time of up to 7 days causes the number of HA crystals to increase with somewhat formation of the characteristic shape of the HA layer. Lastly, it is clearly evident from Fig. 3c that soaking the same sample in SBF solution for 10 days leads to the formation of a dense layer with few HA crystals. This indicates that the sample needs additional time to crystallize all the crystals formed or that another layer is starting to form. As discussed above, the soaking time improves the formation of the apatite layer on the surface of the same sample.

Undoubtedly, the perfect match between the bioactive ceramics and the mineral part of human bone is an important factor in forming a strong bond between these interfaces. Given that the formation of the HA 
layer is highly dependent on the surface texture of the examined specimen, glass grains are preferred for many biomedical applications, including antibiotics, gene delivery, and growth factors $[54,55]$.

\subsection{The properties of the prepared glass samples}

\subsubsection{Density}

It cannot be denied that density is considered a fundamental property and can be calculated based on glass composition [56]. The density values for the as-prepared glass specimens were measured and illustrated in Fig. 4. It is interesting to see from this figure that the density decreases with increasing boron contents in the as-prepared samples despite the slight increase in the density value of $\mathrm{B}_{2} \mathrm{O}_{3}(2.46$ $\mathrm{g} / \mathrm{cm}^{3}$ ) compared to that of $\mathrm{P}_{2} \mathrm{O}_{5}\left(2.39 \mathrm{~g} / \mathrm{cm}^{3}\right)$. The reason for this result is that the successive increase in the content of $\mathrm{B}_{2} \mathrm{O}_{3}$, at the expense of $\mathrm{P}_{2} \mathrm{O}_{5}$, increases the number of NBOs as a result of the conversion of some $\mathrm{Q}^{2}$ units to $\mathrm{Q}^{1}$ ones, which was confirmed by the obtained FTIR spectra, that leads to a slight decrease in the density. This explanation is supported by the results discussed by Yamusa et al. [57], who reported that the increase in the number of NBOs in the glass structure is responsible for decreasing the density of the glass samples. It should be noted that because $\mathrm{B}_{2} \mathrm{O}_{3}$ is a network former, the density values are not always a good indicator of the packing density within the glass structure [58].

\subsubsection{Mechanical properties}

Generally, the clinical applications of bone substitute materials are greatly affected by their mechanical properties [44]. In this sense, microhardness, fracture toughness, compressive strength, longitudinal and shear velocities, Young's modulus, longitudinal modulus, bulk modulus, shear modulus, and Poisson's ratio of all glasses were measured and illustrated in Figs. 5-8. The figures show the role of increasing $\mathrm{B}_{2} \mathrm{O}_{3}$ contents in improving the mechanical properties of all samples. On the contrary, fracture toughness exhibits an opposite trend to other mechanical properties as it decreases by successive increases in $\mathrm{B}_{2} \mathrm{O}_{3}$ contents. These results can be explained on the basis that the current glass system is composed of three formers, i.e., $\mathrm{SiO}_{2}, \mathrm{P}_{2} \mathrm{O}_{5}$, and $\mathrm{B}_{2} \mathrm{O}_{3}$, along with glass modifiers. When $\mathrm{B}_{2} \mathrm{O}_{3}$ is added to $\mathrm{P}_{2} \mathrm{O}_{5}$, the phosphate glass structure is changed from a link structure to a framework structure due to the formation of $\mathrm{B}-\mathrm{O}-\mathrm{P}$ bonds, which in turn improves the mechanical properties of the investigated samples [59]. Notably, the obtained values of compressive strength and fracture toughness closely match those of cortical bone, i.e., 100-180 MPa and 2-12 MPa.m ${ }^{0.5}$, respectively [60]. Noteworthy, these results are in good agreement with those reported in Ref. [61], which mentioned that the increase of boron content, at the expense of phosphate ones, is responsible for giving the studied glass samples this recorded increase in their mechanical properties. Importantly, the good mechanical properties of these glasses give them a substantial advantage to be used in load-bearing sites [36,37].

\subsection{Finite element model analysis}

Model and boundary condition 
A finite element model (FEM) was created using the ANSYS software to predict the compositions' mechanical characteristics and dynamic behavior. Four different concentrations of boric acid have varied the designs of the investigated work; hence this variation reflected on the experimental mechanical properties discussed before. The studied compositions samples were modeled according to the real data acquired from the experimental tests. The isotropic elasticity parameters such as Young's modulus, density, and the maximum compressive stress were fed to the model for each composition. The samples were designed to match the purpose of its application; for example, the biomedical plate used to fix the bone was modeled, as shown in Fig. 9. With a Young's modulus of $20 \mathrm{GPa}$ and a Poisson ratio of 0.3 , the bone material is considered to be isotropic and homogeneous throughout the bone. Hence the calculations will be based on the load response on the investigated plates; we have used isotropy herein for convenience sake because our goal is to demonstrate the effect of different loads on the plates that are fixed to the bone.

Meshing techniques and size greatly influence the accuracy of the solution result for both mechanical and dynamic behavior. Many attempts were made to select the greatest possible resolution that could be attained and matched with the experimental test. According to the FEA solutions and meshing types, three meshing approaches were examined to choose the closest value to the experimental test: multizone, triangles, and quadrilateral dominant. The investigated model uses the Quad/Tri meshing method with 8108 nodes and 4166 elements. Boundary conditions were assigned using fixed support from one side of the investigated model. Static structural module and eigenvalue buckling were utilized to predict and model the mechanical properties of the studied compositions. At the same time, Modal analysis was conducted for the modeled sample; the first six mode shapes and their natural frequencies were computed. $10 \mathrm{~N}$ force was applied at the end of the plate to calculate and plot the frequency response function. Furthermore, the harmonic response module was used in its superposition mode as part of the solution method, and the solution interval was set to 100 increment points to increase the resolution of the results in the frequency response function (FRF) plot.

\subsubsection{Deflection effect}

Fig. 10 shows the effect of the applied load on the deflection of the investigated compositions. It is evident from the figure that there is a linear relationship between increased loads and their effect on the deflection of the structure. As the $\mathrm{B}_{2} \mathrm{O}_{3}$ contents increased, the structure deflection decreased. This can be attributed to the increase in the composition strength. The improvement in the resistance to deflect (from 0 to $\left.25 \mathrm{~mol} \% \mathrm{~B}_{2} \mathrm{O}_{3}\right)$ is achieved by $39 \%$. While from ( 0 to $\left.10 \mathrm{~mol} \% \mathrm{~B}_{2} \mathrm{O}_{3}\right)$ was enhanced by noticed 8.11 $\%$. A significant improvement is achieved when increasing the $\mathrm{B}_{2} \mathrm{O}_{3}$ contents are more than 20 (mol.\%).

\subsubsection{Buckling analysis}

Recent research shows that these structural glasses can sustain substantial dead loads caused by body weight. Because of their great slenderness, these glass samples are prone to buckling failure and must thus be examined under this probable limit condition. Analytical buckling analysis of glass columns may 
typically be conducted using a conventional formula for columns subjected to axial stresses. Fig. 11-a shows the effect of applied load on load multiplier; hence, buckling occurs when a component loses stability, regardless of material strength. This loss of stability happens within the material's elastic range. The load multiplier for all investigated samples was greater than 1; hence the loads applied are fewer than the critical load that can cause buckling. The exponential relationship between the applied load and the load multiplier reflects that increasing loads are getting too close to the critical load, causing the plates to collapse. Using a $1 \mathrm{kN}$ load, the $\mathrm{S} 4$ compositions enhance the buckling behavior by $73 \%$ more than the S1. The buckling deflection takes various behavior during failure mode; Fig. 11-b shows that increasing the boric acid contents in the investigated composition enhances and alerts the failure results from the extra loads. Fig. 12 illustrates the simulation of the primary first sixth buckling failure modes.

\subsubsection{Stress analysis}

The Von-Mises stress determines whether a material will yield or fracture. A material will yield if its value located under load is equal to or greater than its simple tension yield limit. Fig. 13 shows the effect of the different percentages of boric acid on the maximum equivalent stresses. There is no significant impact on the stress value throughout all the investigated compositions, as illustrated in Table 2. By increasing the load, the equivalent Von-Mises stress is increased, and this result logically due to the loads are approaching the yield point.

\subsubsection{Dynamic behavior}

The structures and materials have inherent vibration frequencies at which they will deform, a phenomenon known as resonance. Each natural frequency is connected with a mode, which is a shape that describes the deformation of the structure. The first mode is the lowest frequency at which deformation occurs. When a structure vibrates, the initial mode generally specifies the highest loads in the structure or how that structure will interact with the rest of the system surrounding it. The FEA showed the effect of different compositions properties on the dynamics behavior; hence, the resonant frequency on the most important parameters used to identify the dynamic behavior of materials subjected to dynamic or excitation sources near the structure's natural frequency. The modal analysis was used to predict the resonant frequency throughout the various mode shapes. In the current investigation, the primary sixth modes are simulated as shown in Fig. 14, and the corresponding resonant frequencies are represented in Fig. 15. As the excitation source is increased, the resonant frequency moves from resonant mode to another at a specific value. The higher resonant frequencies were achieved by $\left(25\right.$ mol. $\left.\% \mathrm{~B}_{2} \mathrm{O}_{3}\right)$ content. The FRF was plotted in Fig. 16; at the first mode shape, the maximum resonant frequency was $360.67 \mathrm{~Hz}$ for the composition ( $25 \mathrm{~mol} . \% \mathrm{~B}_{2} \mathrm{O}_{3}$ ), while the minimum was recorded $232.66 \mathrm{~Hz}$ for the (0 mol.\% $\mathrm{B}_{2} \mathrm{O}_{3}$ ). According to these results, increasing the mechanical properties of isotropic parameters leads to an increase in the natural frequency value.

\section{Conclusions}


The in vitro bioactivity of $\mathrm{CaO}-\mathrm{Na}_{2} \mathrm{O}-\mathrm{SiO}_{2}-\mathrm{B}_{2} \mathrm{O}_{3}-\mathrm{P}_{2} \mathrm{O}_{5}$ glasses towards simulated body fluid (SBF) was evaluated for prolonged soaking times of up to 10 days. The XRD patterns pointed out that the increased boron content in the glass compositions promoted the formation of a HA-like layer on the surfaces of the glass samples, which was in line with that obtained by SEM to give additional evidence to the formation of this layer. Furthermore, the increase in boron content significantly increased the microhardness and chemical durability of these glasses. However, boron caused a slight decrease in fracture toughness. It should be noted that increasing the $\mathrm{B}_{2} \mathrm{O}_{3}$ contents from 0 to $25 \mathrm{~mol} \%$ was responsible for the $39 \%$ increase in the deflecting resistance, considering that this improvement started to be observed when the $\mathrm{B}_{2} \mathrm{O}_{3}$ content was increased by $20 \mathrm{~mol} \%$. Also, a glass sample containing $25 \mathrm{~mol} \% \mathrm{~B}_{2} \mathrm{O}_{3}$ outperforms that containing 0 mol\% $\mathrm{B}_{2} \mathrm{O}_{3}$ by $73 \%$. By increasing the content of $\mathrm{B}_{2} \mathrm{O}_{3}$ in the investigated composition, the failure rate from the extra loads increased. On the other hand, the shear and principles stresses were not affected by the different compositions used in the present investigation. From the results obtained, it can be concluded that $\mathrm{B}_{2} \mathrm{O}_{3}$ has a significant role in enhancing the mechanical and dynamic properties; hence the dynamic properties were improved by increasing the resonance frequency.

\section{Declarations}

\section{Acknowledgment}

This project was funded by the Deanship of Scientific Research (DSR) at King Abdulaziz University, Jeddah, under grant No. (G: 209-980-1442). The author, therefore, acknowledges with thanks DSR for technical and financial support

\section{References}

1. M.A. Taha, R.A. Youness, M.F. Zawrah, Phase composition, sinterability and bioactivity of amorphous nano-CaO-SiO $-\mathrm{CuO}$ powder synthesized by sol-gel technique, Ceram. Int. 46 (2020): 24462-24471.

2. R.A. Youness, M.A. Taha, M.A. Ibrahim, The influence of various zirconia contents on crystallite sizes, shrinkage, and physical and mechanical properties of hydroxyapatite-based nanobiocomposites, Egypt. J. Chem. 64 (3) (2021): 1347-1352 (2021).

3. R.A. Youness, M.A. Taha, H. Elhaes, M. Ibrahim, Molecular modeling, FTIR spectral characterization and mechanical properties of carbonated-hydroxyapatite prepared by mechanochemical synthesis, Mater. Chem. Phys. 190 (2017): 209-218.

4. R.A. Youness, M.A. Taha, H. Elhaes, M. Ibrahim, Preparation, Fourier transform infrared characterization and mechanical properties of hydroxyapatite nanopowders, J. Comput. Theor. Nanosci. 14 (2017): 2409-2415.

5. L.L. Hench, H.A. Paschall, Direct chemical bond of bioactive glass-ceramic materials to bone and muscle, Biomed. Mater. Res. 7 (1973): 25-42. 
6. M.E. Santocildes-Romero, A. Crawford, P.V. Hatton, R.L. Goodchild, I.M. Reaney, A.M. Cheryl, The osteogenic response of mesenchymal stromal cells to strontium-substituted bioactive glasses, Tissue Eng. Regen. Med. 9 (2015): 619-631.

7. L.C. Gerhardt, A.R. Boccaccini, Bioactive glass and glass-ceramic scaffolds for bone tissue engineering, Mater. 3 (2010): 3867-3910.

8. L.L. Hench, The story of Bioglass ${ }^{\circledR}$, J. Mater. Sci.: Mater. Med. 17 (2006): 967-978.

9. S.L. Schmitz, B. Widholz, C. Essers, M. Becker, D.U. Tulyaganov, A. Moghaddam, G. de Juan, F. Westhauser, Superior biocompatibility and comparable osteoinductive properties: sodium-reduced fluoride-containing bioactive glass belonging to the $\mathrm{CaO}-\mathrm{MgO}-\mathrm{SiO}_{2}$ system as a promising alternative to $45 S 5$ bioactive glass, Bioact. Mater. 5 (1) (2020): 55-65.

10. A.F.F. Camargo, A.M. Baptista, R. Natalino, O.P. De Camargo, Bioactive glass in cavitary bone defects: a comparative experimental study in rabbits, Acta Ortop. Bras. 23 (4) (2015): 202-207.

11. Manupriya, K.S. Thind, K. Singh, V. Kumar, G. Sharma, D.P. Singh, D. Singh, Compositional dependence of in vitro bioactivity in sodium calcium borate glasses, Phys. Chem. Sol. 70 (2009): 1137-1141.

12. R.A. Youness, M.A. Taha, A. El-Kheshen, N. El-Faramawy, M. Ibrahim, In vitro bioactivity evaluation, antimicrobial behavior and mechanical properties of cerium-containing phosphate glasses, Mater. Res. Express 6 (2019): 1-13.

13. R.A. Youness, M.A. Taha, M. Ibrahim, A. El-Kheshen, FTIR spectral characterization, mechanical properties of La-doped phosphate-based bioactive glasses, Silicon 10 (2018): 1151-1159.

14. S. Sadeghazade, R. Emadi, H. Ghomi, Mechanical alloying synthesis of forsterite-diopside nanocomposites powder for using in tissue engineering, Ceramics-Silikaty 59 (1) (2015): 1-5.

15. K.A. Hing, P.A. Revell, N. Smith, Effect of silicon level on rate, quality and progression of bone healing within silicate-substituted porous hydroxyapatite scaffolds, Biomaterials 27 (2006): 5014-5026.

16. M.A. Taha, R.A. Youness, M. Ibrahim, Biocompatibility, physico-chemical and mechanical properties of hydroxyapatite-based silicon dioxide nanocomposites for biomedical applications, Ceram. Int. 46 (2020): 23599-23610.

17. R. Samudrala, P. Abdul Azeem, V. Penugurti, B. Manavathi, Cytocompatibility studies of titania-doped calcium borosilicate bioactive glasses in-vitro. Mater, Sci. Eng. C 77 (2017): 772-779.

18. P. Balasubramanian, T. Büttner, V.M. Pacheco, A.R. Boccaccini, Boron-containing bioactive glasses in bone and soft tissue engineering, J. Eur. Ceram. Soc. 38 (3) (2018): 855-869.

19. F.H. Nielsen, Is boron nutritionally relevant?, Nutr. Rev. 66 (4) (2008): 183-191.

20. S. Zahid, A.T. Shah, A. Jamal, A.A. Chaudhry, A.S. Khan, A.F. Khan, N. Muhammad, I. ur Rehman, Biological behavior of bioactive glasses and their composites, RSC Adv. 6 (2016): 70197-70214.

21. A.M. Deliormanli, In vitro assessment of degradation and bioactivity of robocast bioactive glass scaffolds in simulated body fluid, Ceram. Int. 38 (2012): 6435-6444. 
22. A. Saranti, I. Koutselas, M.A. Karakassides, Bioactive glasses in the system $\mathrm{CaO}-\mathrm{SiO}_{2}-\mathrm{B}_{2} \mathrm{O}_{3}$ : preparation, structural study and in vitro evaluation, Non-Cryst. Solids 352 (2006): 390-398.

23. H. Fu, M.N. Rahaman, D.E. Day, W. Huang, Effect of pyrophosphate ions on the conversion of calcium-lithium-borate study glass to hydroxyapatite in aqueous phosphate solution, J. Mater. Sci. Mater. Med. 21 (10) (2010): 2733-2741.

24. A. Yao, D. Wang, H. Wenhai, Q. Fu, M.N. Rahaman, D.E. Day, In vitro bioactive characteristics of borate-based glasses with controllable degradation behavior, Am. Ceram. Soc. 90 (1) (2007): 303306.

25. W. Huang, D.E. Day, K. Kittiratanapiboon, M.N. Rahaman, Kinetics and mechanisms of the conversion of silicate (45S5), borate and borosilicate glasses to hydroxyapatite in dilute phosphate solutions, Mater. Sci. Mater. Med. 17 (2006): 583-596.

26. K.M.Z. Hossain, U. Patel, Development of microspheres for biomedical applications: a review, Prog. Biomater. 4 (2015): 1-19.

27. E.M.A. Khalil, R.A. Youness, M.S. Amer, M.A. Taha, Mechanical properties, in vitro and in vivo bioactivity assessment of $\mathrm{Na}_{2} \mathrm{O}-\mathrm{CaO}-\mathrm{B}_{2} \mathrm{O}_{3}-\mathrm{SiO}_{2}$ glass-ceramics, Ceram. Int. 44 (2018): 7867-7876.

28. E.P. Erasmus, R. Sule, O.T. Johnson, J. Massera, I. Sigalas, In vitro evaluation of porous borosilicate, borophosphate and phosphate bioactive glasses scaffolds fabricated using foaming agent for bone regeneration, Sci. Reports 8 (2018): 1-13.

29. N. Sharmin, M.S. Hasan, A.J. Parsons, D. Furniss, C.A. Scotchford, I. Ahmed, C.D. Rudd, Effect of boron addition on the thermal, degradation, and cytocompatibility properties of phosphate-based glasses, BioMed Res. Int. 2013 (2013): 1-12.

30. D.E. Abulyazied, A.M. Alturki, R.A. Youness, H.M. Abomostafa, Synthesis, structural and biomedical characterization of hydroxyapatite/borosilicate bioactive glass nanocomposites, J. Inorg. Organomet. Polym. Mater. (2021) In Press.

31. M. Fabert, N. Ojha, E. Erasmus, M. Hannula, M. Hokka, J. Hyttinen, J. Rocherullé, I. Sigalas, J. Massera, Crystallization and sintering of borosilicate bioactive glasses for application in tissue engineering, J. Mater. Chem. B 5 (2017) 4514.

32. X. Liu, W. Huang, H. Fu, A. Yao, D. Wang, H. Pan, W.W. Lu, X. Jiang, X. Zhang, Bioactive borosilicate glass scaffolds: in vitro degradation and bioactivity behaviors, J. Mater. Sci. Mater. Med. 20 (6) (2009): 1237-1243.

33. M. Ren, X. Lu, L. Deng, P.-H. Kuo, J. Du, $\mathrm{B}_{2} \mathrm{O}_{3} / \mathrm{SiO}_{2}$ substitution effect on structure and properties of $\mathrm{Na}_{2} \mathrm{O}-\mathrm{CaO}-\mathrm{SrO}-\mathrm{P}_{2} \mathrm{O}_{5}-\mathrm{SiO}_{2}$ bioactive glasses from molecular dynamics simulations, Phys. Chem. Chem. Phys. 20 (2018) 14090.

34. S. Prasad, A. Gaddam, A. Jana, S. Kant, P.K. Sinha, S. Tripathy, K. Annapurna, J.M.F. Ferreira, A.R. Allu, $\mathrm{K}$. Biswas, Structure and stability of high $\mathrm{CaO}$ - and $\mathrm{P}_{2} \mathrm{O}_{5}$-containing silicate and borosilicate bioactive glasses, J. Phys. Chem. B 123 (2019): 7558-7569. 
35. N.F. Yusof, K.H. Kubulat, N.A. Badrulzaman, M.A.M. Nor, The effect of boron oxide on phosphate ion released from borosilicate glass in seawater, Mater. Sci. Forum 840 (2016): 24-28.

36. T. Kokubo, H. Takadama, How useful is SBF in predicting in vivo bone bioactivity, Biomater. 27 (15) (2006): 2907-2915.

37. T. Kokubo, H. Kushitani, S. Sakka, T. Kitsugi, T. Yamamuro, Solutions able to reproduce in vivo surface-structure changes in bioactive glass-ceramics A-W, J. Biomed. Mater. Res. A 24 (1990): 721734.

38. R.L. Siqueira, E.D. Zanotto, The influence of phosphorus precursors on the synthesis and bioactivity of $\mathrm{SiO}_{2}-\mathrm{CaO}-\mathrm{P}_{2} \mathrm{O}_{5}$ sol-gel glasses and glass-ceramics, J. Mater. Sci. Mater. Med. 24 (2013): 365-379.

39. M.F. Zawrah, M.A. Taha, H. Abo Mostafa, In-situ formation of $\mathrm{Al}_{2} \mathrm{O}_{3} / \mathrm{Al}$ core-shell from waste material: production of porous composite improved by graphene, Ceram. Int. 44 (2018): 1069310699.

40. M.F. Zawrah, R.A. Essawy, H.A. Zayed, A.H. Abdel-Fattah, M.A. Taha, Mechanical alloying, sintering and characterization of $\mathrm{Al}_{2} \mathrm{O}_{3}-20$ wt.\%-Cu nanocomposite, Ceram Int. 40 (2014): 31-38.

41. R.A. Youness, M.A. Taha, M. Ibrahim, In vitro bioactivity, molecular structure and mechanical properties of zirconia-carbonated hydroxyapatite nanobiocomposites sintered at different temperatures, Mater. Chem. Phys. 239 (2020) 122011.

42. R.A. Youness, M.A. Taha, M. Ibrahim, In vitro bioactivity, physical and mechanical properties of carbonated-fluoroapatite during mechanochemical synthesis, Ceram. Int. 44 (2018): 21323-21329.

43. R.A. Youness, M.A. Taha, M.A. Ibrahim, Effect of sintering temperatures on the in vitro bioactivity, molecular structure and mechanical properties of titanium/carbonated hydroxyapatite nanobiocomposites, J. Mol. Struct. 1150 (2017): 188-195.

44. R.A. Youness, M.A. Taha, A.A. El-Kheshen, M. Ibrahim, Influence of the addition of carbonated hydroxyapatite and selenium dioxide on mechanical properties and in vitro bioactivity of borosilicate inert glass, Ceram. Int. 44 (2018): 20677-20685.

45. N. Sharmin, F. Gu, I. Ahmed, A.J. Parsons, Compositional dependency on dissolution rate and cytocompatibility of phosphate-based glasses: effect of $\mathrm{B}_{2} \mathrm{O}_{3}$ and $\mathrm{Fe}_{2} \mathrm{O}_{3}$ addition, J. Tiss. Eng. 8 (2017): 1-10.

46. R.K. Singh, G.P. Kothiyal, A. Srinivasan, In vitro evaluation of bioactivity of $\mathrm{CaO}-\mathrm{SiO}_{2}-\mathrm{P}_{2} \mathrm{O}_{5}-\mathrm{Na}_{2} \mathrm{O}-$ $\mathrm{Fe}_{2} \mathrm{O}_{3}$ glasses, Appl. Surface Sci. 255 (2009): 6827-6831.

47. Y. Li, A. Coughlan, F.R. Laffir, D. Pradhan, N.P. Mellott, A.W. Wren, Investigating the mechanical durability of bioactive glasses as a function of structure, solubility and incubation time, J. Non-Cryst. Solids 380 (2013): 25-34.

48. W. Ho, C. Lai, H. Hsu, S. Wu, Surface modification of a Ti-7. 5Mo alloy using $\mathrm{NaOH}$ treatment and Bioglass ${ }^{\circledR}$ coating, J. Mater. Sci. Mater. Med. 21 (2010): 1479-1488.

49. W.S. AbuShanab, E.B. Moustafa, M.A. Taha, R.A. Youness, Synthesis and structural properties characterization of titania/ 
zirconia/calcium silicate nanocomposites for biomedical applications, Appl. Phys. A 126 (10) (2020): 1-12.

50. H. Kamal, Characterization of silver-borate glasses for biomedical applications, IOSR-JAP 11 (3) (2019): 18-26.

51. A. Tilocca, Structural models of bioactive glasses from molecular dynamics simulations, Proc. R. Soc. A 465 (2009): 1003-1027.

52. M.A. Marzouk, F.H. ElBatal, N.A. Ghoneim, In vitro bioactivity behavior of modified multicomponent borate glasses containing dopants of $\mathrm{Ag}_{2} \mathrm{O}, \mathrm{CuO}, \mathrm{CeO}_{2}$ or $\mathrm{V}_{2} \mathrm{O}_{5}$, Appl. Phys. A 124 (2018) 1-12.

53. S. Ferraris, S. Yamaguchi, N. Barbani, M. Cazzola, C. Cristallini, M. Miola, E. Vernè, S. Spriano, Bioactive materials: in vitro investigation of different mechanisms of hydroxyapatite precipitation, Acta Biomater. 102 (2020): 468-480.

54. P. Kumar, B.S. Dehiya, A. Sindhu, Bioceramics for hard tissue engineering applications: a review, Int. J. Appl. Eng. Res. 13 (5) (2018): 2744-2752.

55. I. Ahmed, M. Lewis, I. Olsen, J.C. Knowles, Phosphate glasses for tissue engineering: Part 1. Processing and characterisation of a ternary-based $\mathrm{P}_{2} \mathrm{O}_{5}-\mathrm{CaO}-\mathrm{Na}_{2} \mathrm{O}$ glass system, Biomaterials 25 (3) (2004): 491-499.

56. U.B. Chanshetti, V.A. Shelke, S.M. Jadhav, S.G. Shankarwar, T.K. Chondhekar, A.G. Shankarwar, V. Sudarsan, M.S. Jogad, Density and molar volume studies of phosphate glasses, Phys. Chem. Technol. 9 (1) (2011): 29-36.

57. Y.A. Yamusa, R. Hussin, W.N.W. Shamsuri, S.A. Dalhatu, A.M. Aliyu, I. Bulus, Structural characterization of sulphate borophosphate glasses containing calcium oxide, Mal. J. Fund. Appl. Sci. 13 (3) (2017): 193-197.

58. D. Qiu, P. Guerry, I. Ahmed, D.M. Pickup, A high-energy X-ray diffraction, 31P and 11B solid-state NMR study of the structure of aged sodium borophosphate glasses, Mater. Chem. Phys. 111 (2-3) (2008): 455-462.

59. D. Carta, D. Qiu, P. Guerry, I. Ahmed, E.A. Abou Neel, J.C. Knowles, M.E. Smith, R.J. Newport, The effect of composition on the structure of sodium borophosphate glasses, Non-Cryst. Solids 354 (31) (2008): 3671-3677.

60. C. Gao, S. Peng, P. Feng, C. Shuai, Bone biomaterials and interactions with stem cells, Bone Res. 5 (2017) 17059.

61. K.V. Shah, M. Goswami, M.N. Deo, A. Sarkar, S. Manikandan, Shrikhande, G.P. Kothiyal, Effect of $\mathrm{B}_{2} \mathrm{O}_{3}$ addition on microhardness and structural features of $40 \mathrm{Na}_{2} \mathrm{O}-10 \mathrm{BaO}-\mathrm{xB}_{2} \mathrm{O}_{3}-(50-\mathrm{x}) \mathrm{P}_{2} \mathrm{O}_{5}$ glass system, Bull Mater. Sci. 29 (1) (2006): 43-48.

\section{Tables}

Table 1. Nominal composition (mol.\%) of borophosphosilicate glasses 


\begin{tabular}{|llllll|}
\hline Sample code & $\mathrm{B}_{\mathbf{2}} \mathrm{O}_{\mathbf{3}}$ & $\mathrm{SiO}_{\mathbf{2}}$ & $\mathrm{Na}_{\mathbf{2}} \mathbf{O}$ & $\mathrm{CaO}$ & $\mathrm{P}_{\mathbf{2}} \mathrm{O}_{\mathbf{5}}$ \\
\hline $\mathrm{S} 1$ & 0 & 10 & 25 & 20 & 45 \\
\hline S2 & 10 & 10 & 25 & 20 & 35 \\
\hline S3 & 20 & 10 & 25 & 20 & 25 \\
\hline S4 & 25 & 10 & 25 & 20 & 20 \\
\hline
\end{tabular}

Table 2. The average value of the equivalent stresses 
Maximum Shear Stress MPa

\begin{tabular}{|c|c|c|c|c|}
\hline Load & $0 \mathrm{~mol} . \% \mathrm{~B}_{2} \mathrm{O}_{3}$ & $10 \mathrm{~mol} . \% \mathrm{~B}_{2} \mathrm{O}_{3}$ & $20 \mathrm{~mol} . \% \mathrm{~B}_{2} \mathrm{O}_{3}$ & $25 \mathrm{~mol} . \% \mathrm{~B}_{2} \mathrm{O}_{3}$ \\
\hline 100 & 2.58746 & 2.58743 & 2.58739 & 2.58731 \\
\hline 200 & 5.17492 & 5.17485 & 5.17477 & 5.17462 \\
\hline 300 & 7.76239 & 7.76228 & 7.76216 & 7.76193 \\
\hline 400 & 10.34985 & 10.3497 & 10.34954 & 10.34925 \\
\hline 500 & 12.93731 & 12.93713 & 12.93693 & 12.93656 \\
\hline 600 & 15.52477 & 15.52456 & 15.52431 & 15.52387 \\
\hline 700 & 18.11223 & 18.11198 & 18.1117 & 18.11118 \\
\hline 800 & 20.6997 & 20.69941 & 20.69909 & 20.69849 \\
\hline 900 & 23.28716 & 23.28683 & 23.28647 & 23.2858 \\
\hline 1000 & 25.87462 & 25.87426 & 25.87386 & 25.87312 \\
\hline Load & \multicolumn{4}{|c|}{ Maximum Principle Stress MPa } \\
\hline 100 & 0.47932 & 0.47921 & 0.4791 & 0.47888 \\
\hline 200 & 0.95863 & 0.95843 & 0.95819 & 0.95775 \\
\hline 300 & 1.43795 & 1.43764 & 1.43729 & 1.43663 \\
\hline 400 & 1.91727 & 1.91685 & 1.91639 & 1.9155 \\
\hline 500 & 2.39658 & 2.39607 & 2.39548 & 2.39438 \\
\hline 600 & 2.8759 & 2.87528 & 2.87458 & 2.87326 \\
\hline 700 & 3.35522 & 3.3545 & 3.35368 & 3.35213 \\
\hline 800 & 3.83454 & 3.83371 & 3.83278 & 3.83101 \\
\hline 900 & 4.31385 & 4.31292 & 4.31187 & 4.30988 \\
\hline 1000 & 4.79317 & 4.79214 & 4.79097 & 4.78876 \\
\hline
\end{tabular}

Figures 


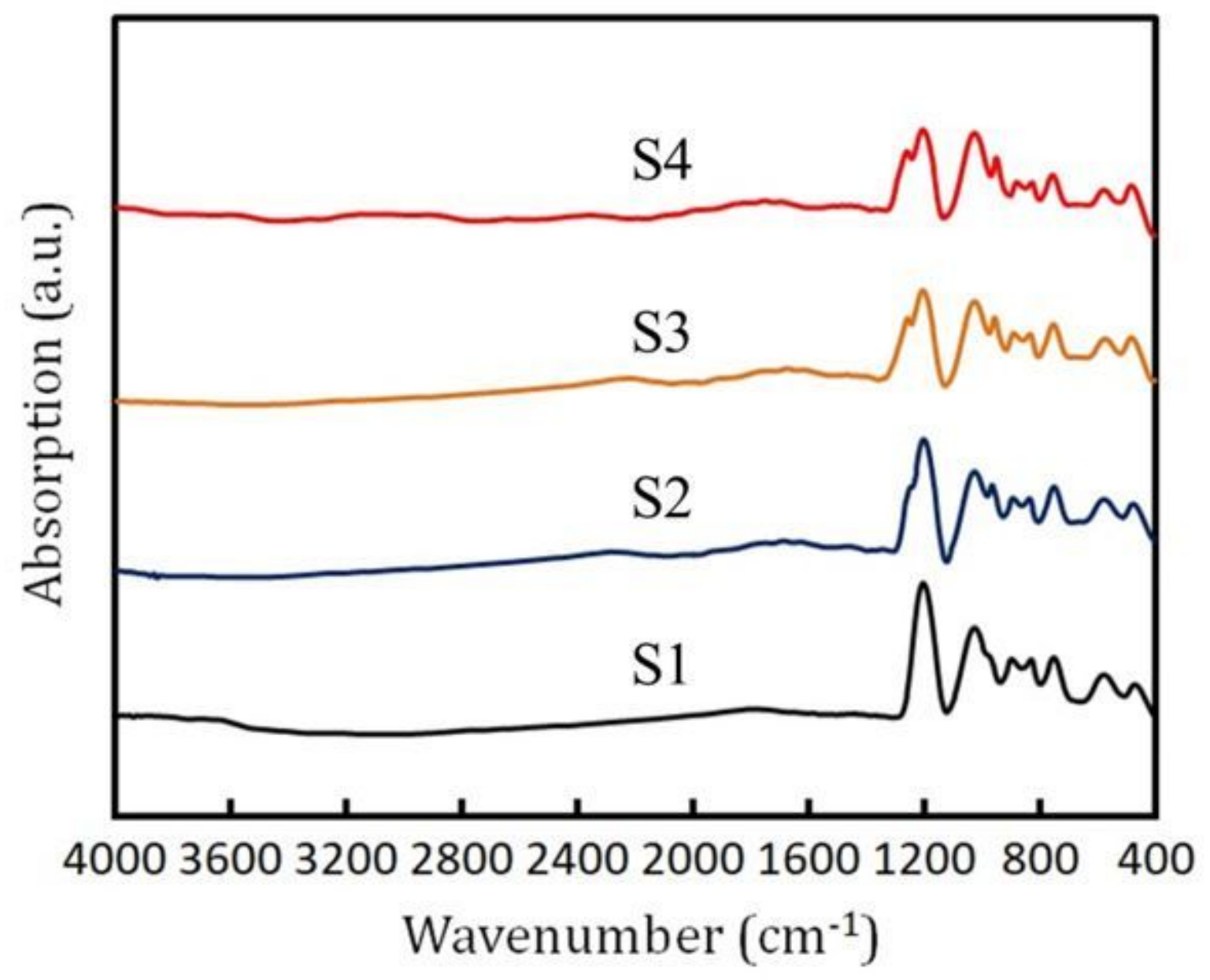

Figure 1

FTIR absorption spectra of phosphosilicate glasses with successive increase in B2O3 content from 0 to 25 wt.\%. 

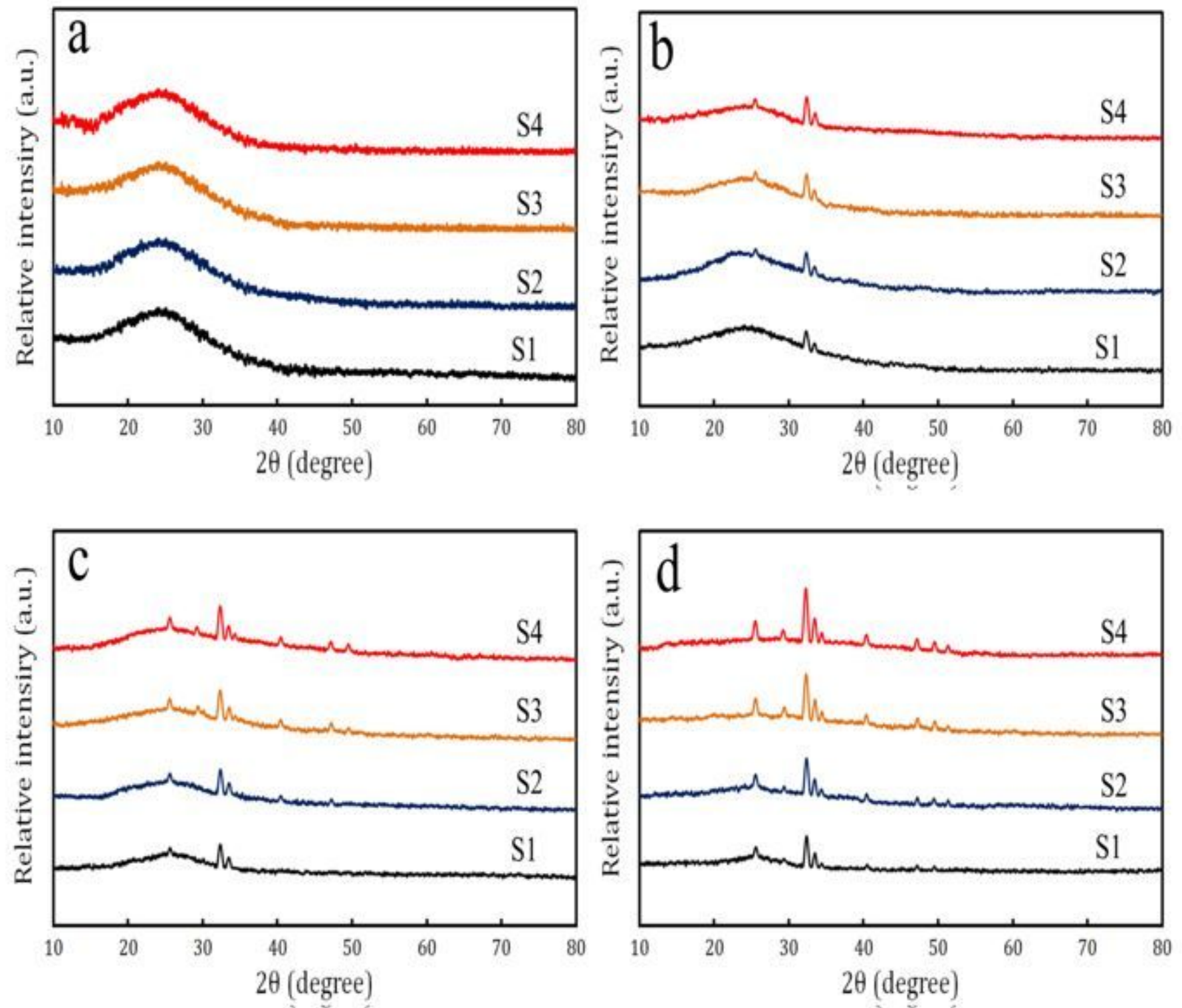

Figure 2

XRD patterns of a) as-prepared glasses and reacted glasses in SBF solution for b) 3 days, c) 7 days and d) 10 days. 

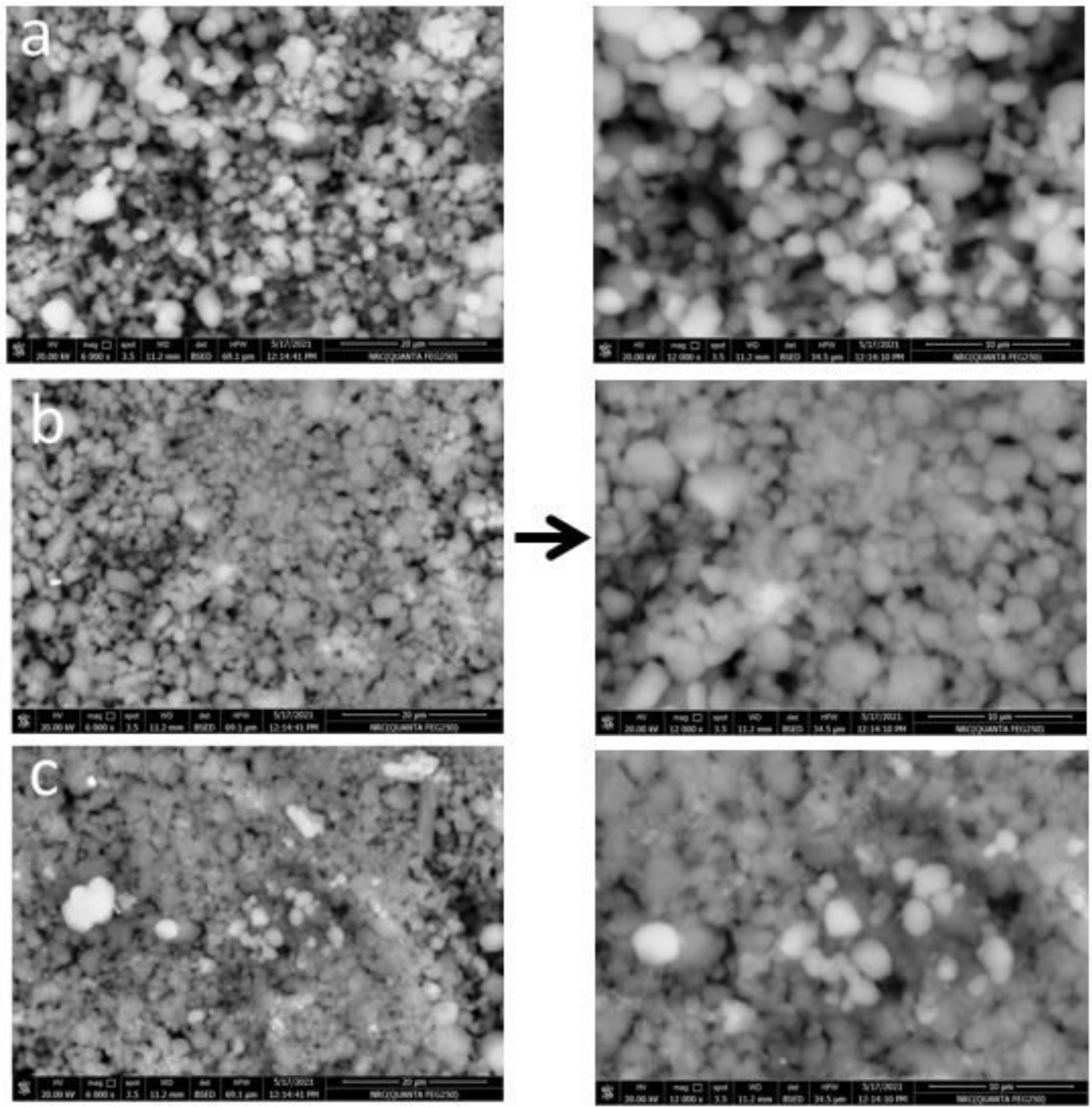

Figure 3

SEM images of S4 sample after soaking in SBF solution for a) 3 days, b) 7 days and c) 10 days at two different magnification powers. 


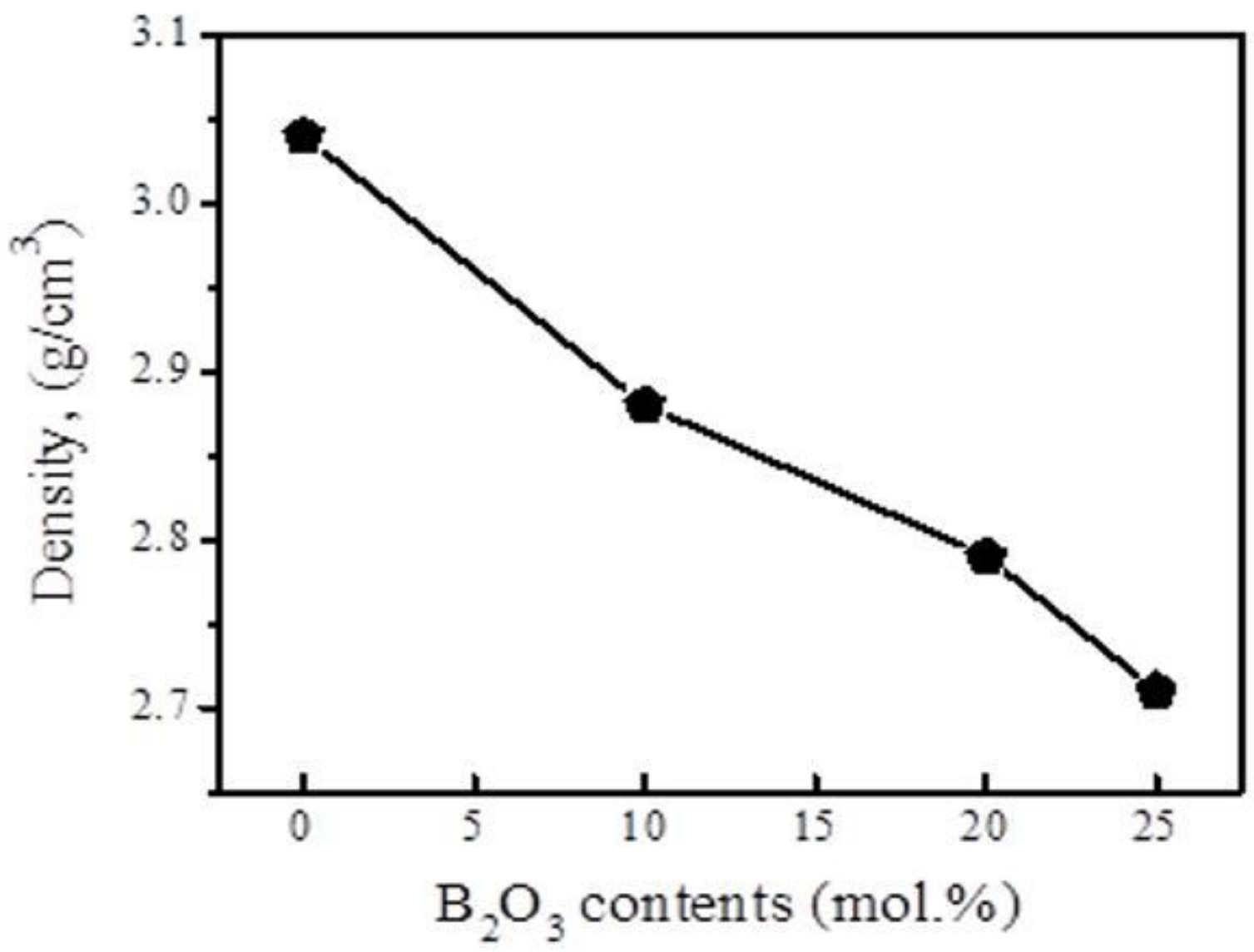

Figure 4

Bulk density of all prepared glass samples with different contents of B2O3 (mol.\%) 


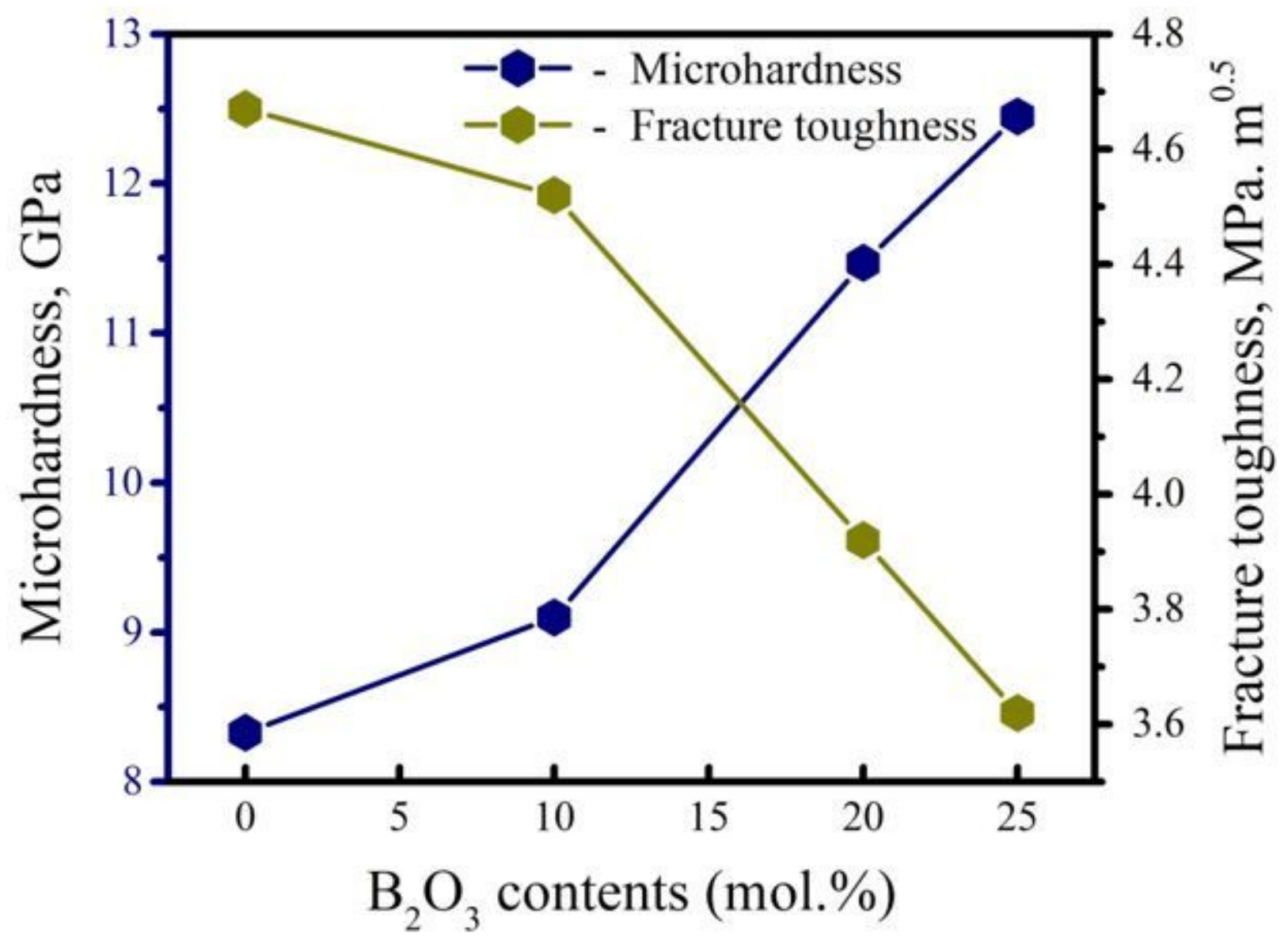

Figure 5

Microhardness and fracture toughness of all glass samples versus B2O3 contents (mol.\%) 


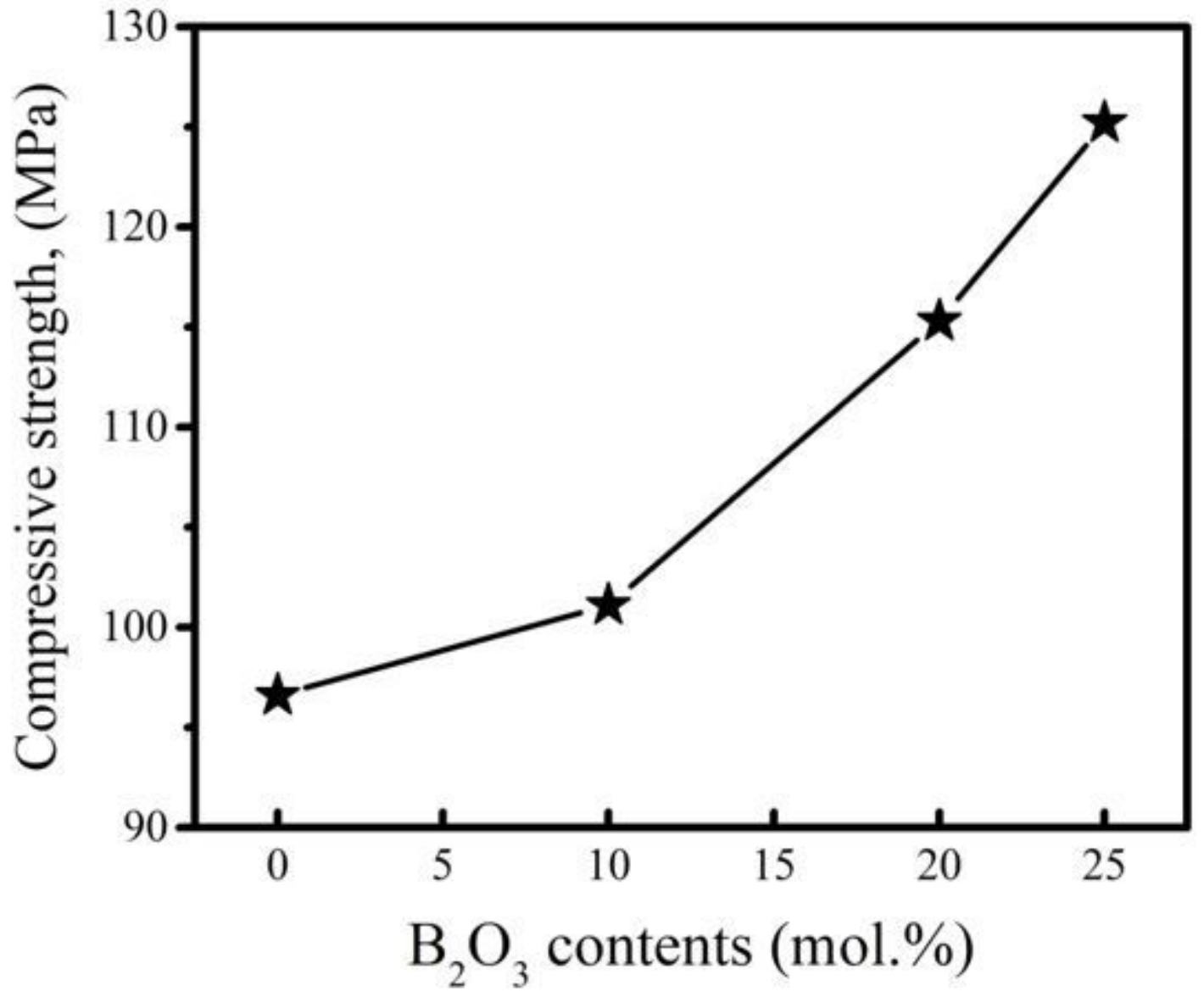

Figure 6

Compressive strength of S1, S2, S3 and S4 glass samples 


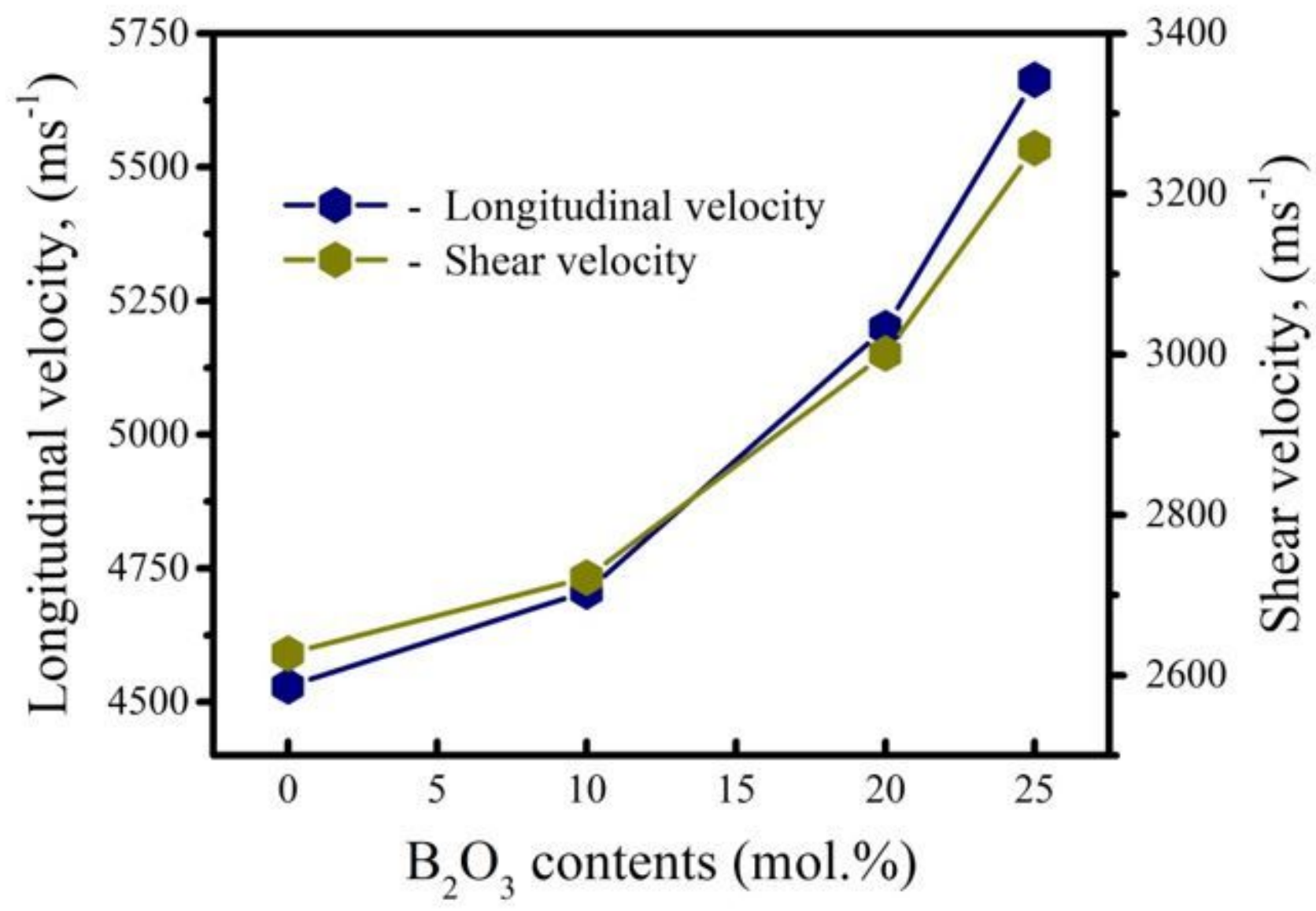

Figure 7

Longitudinal and shear ultrasonic velocities versus different boron oxide contents (mol.\%). 

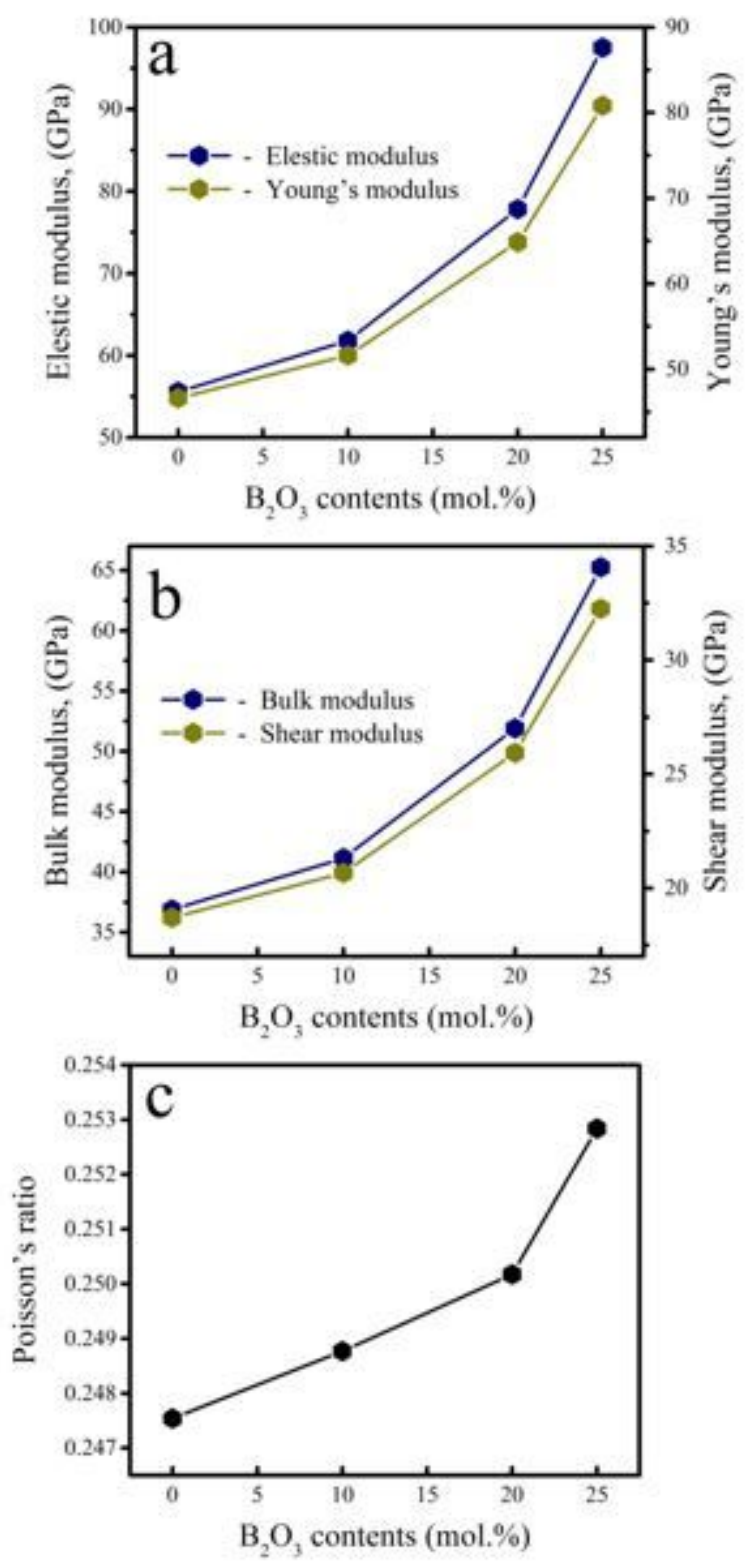

Figure 8

a) Young's and elastic moduli, b) bulk and shear moduli and C) Poisson's ratio of borophosphosilicate glass samples. 


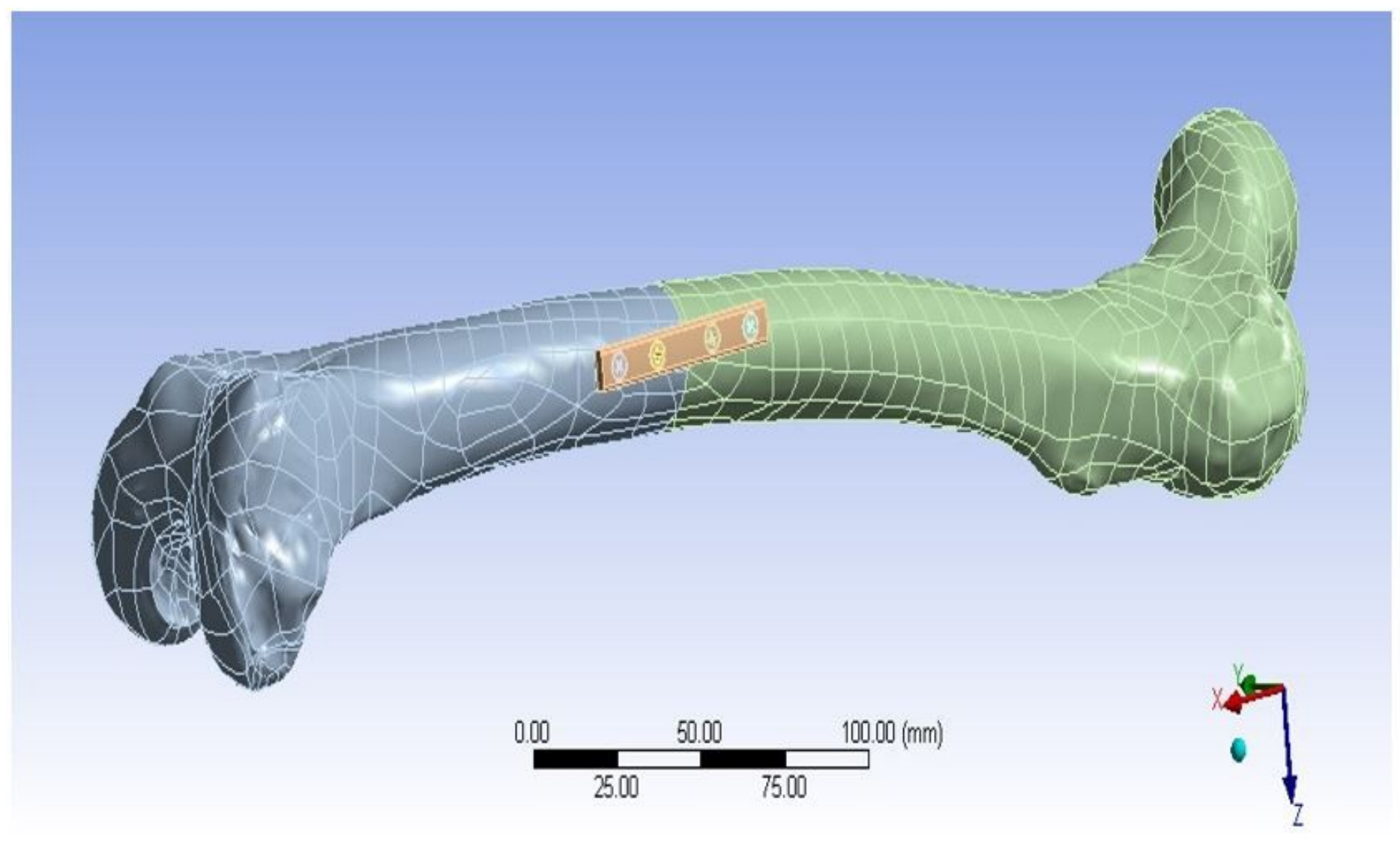

Figure 9

Modeling and the assembly of the investigated plate mounted on the bone 


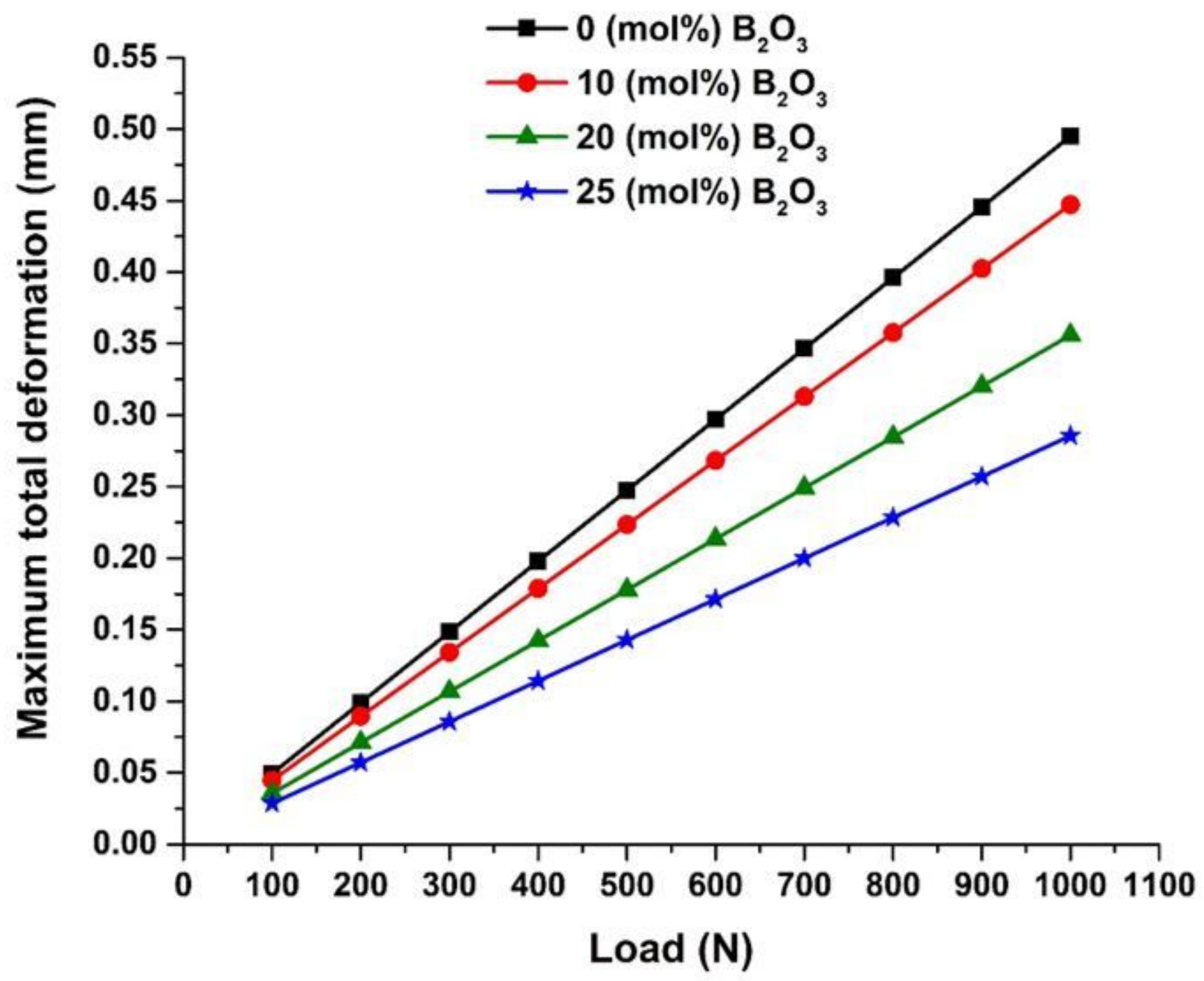

Figure 10

Effect of the applied static load on the total deflection 

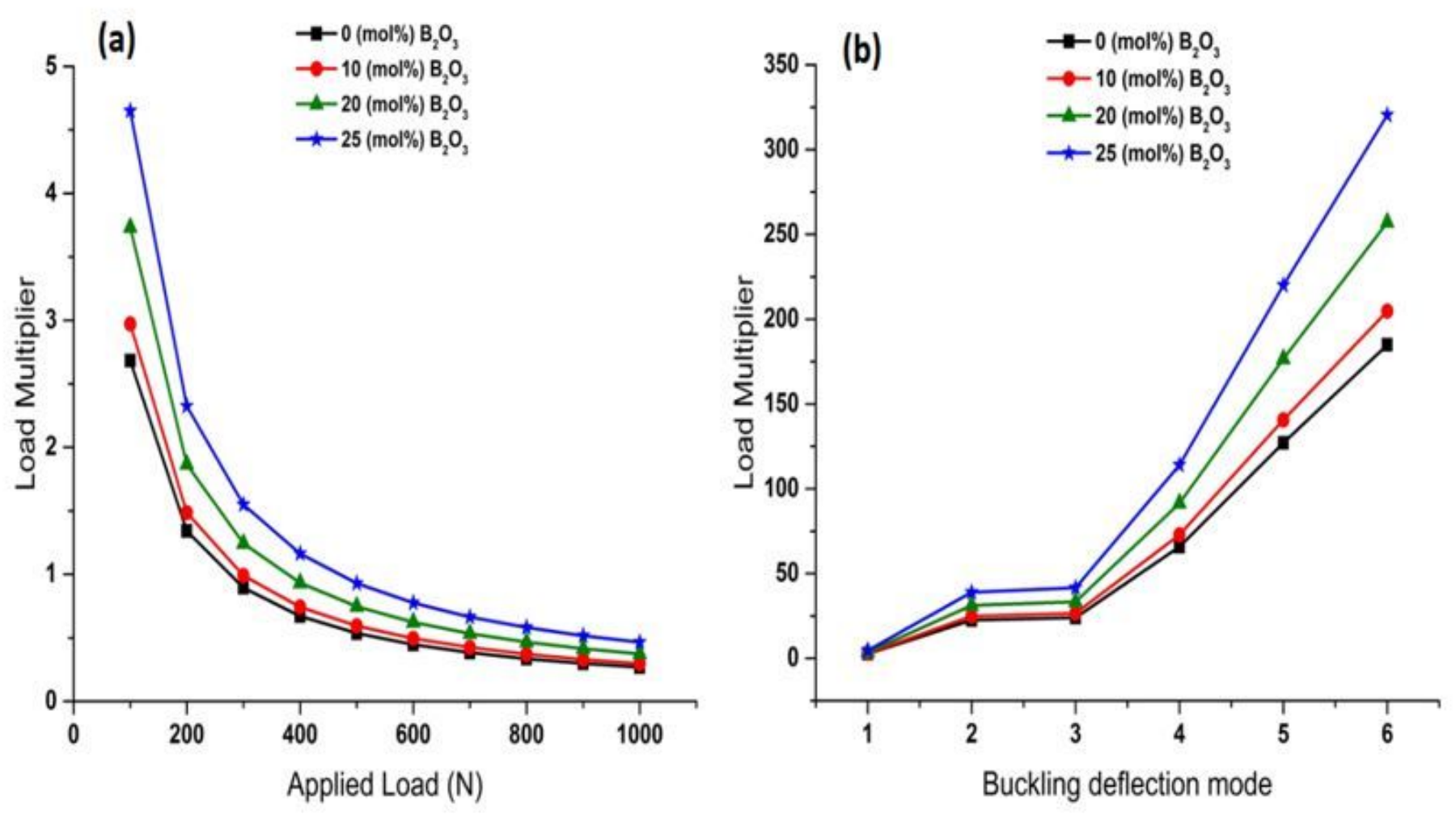

Figure 11

(a) The relationship between the applied load and the critical point of failure and (b) effect of B2O3 (mol.\%) contents on the buckling deflection mode 


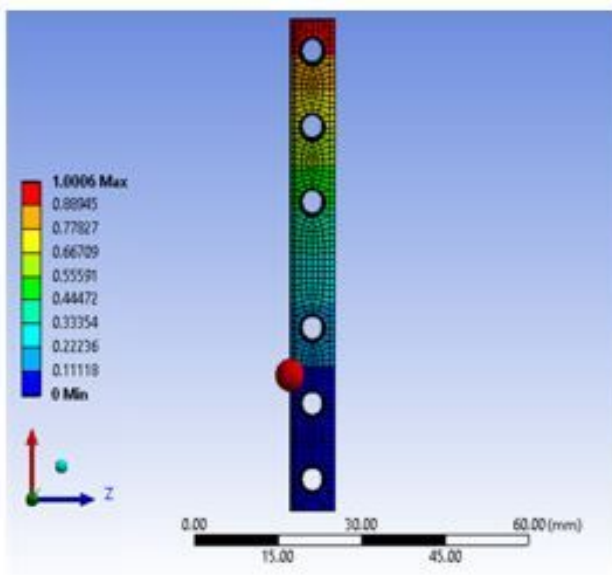

$1^{\text {st }}$ Buckling mode

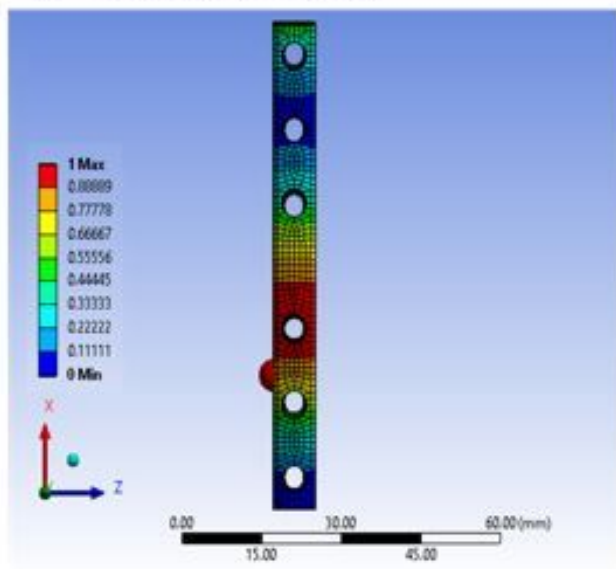

$4^{\text {th }}$ Buckling mode

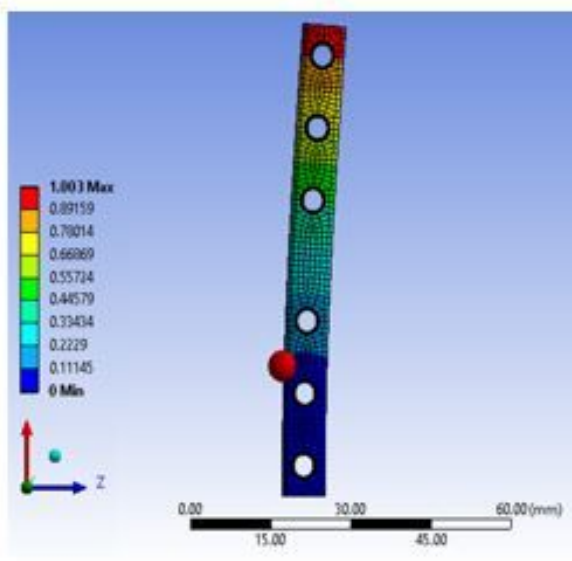

$2^{\text {nd }}$ Buckling mode

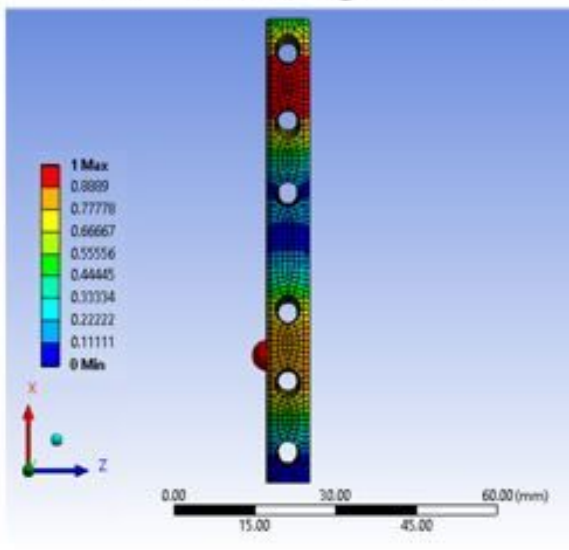

$5^{\text {th }}$ Buckling mode

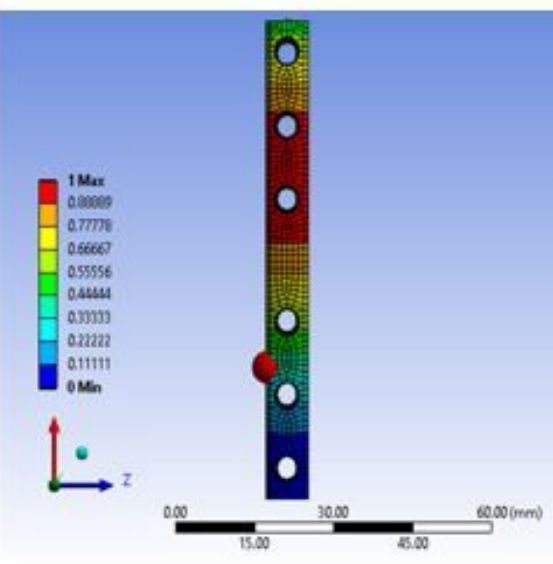

$3^{\text {rd }}$ Buckling mode

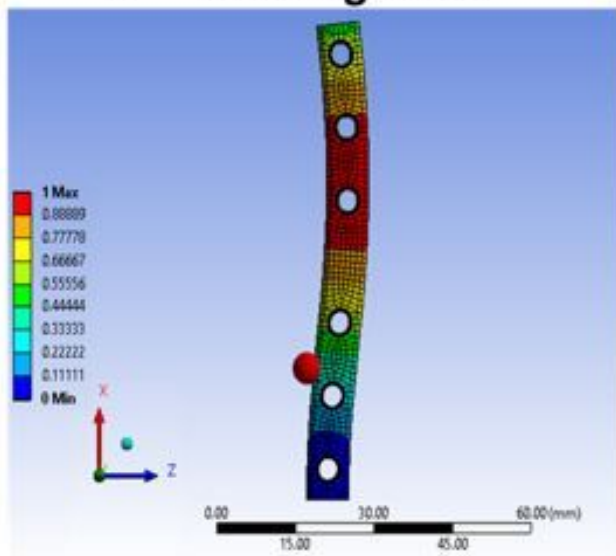

$6^{\text {th }}$ Buckling mode

Figure 12

Buckling total deformation mode of the investigated glass samples 

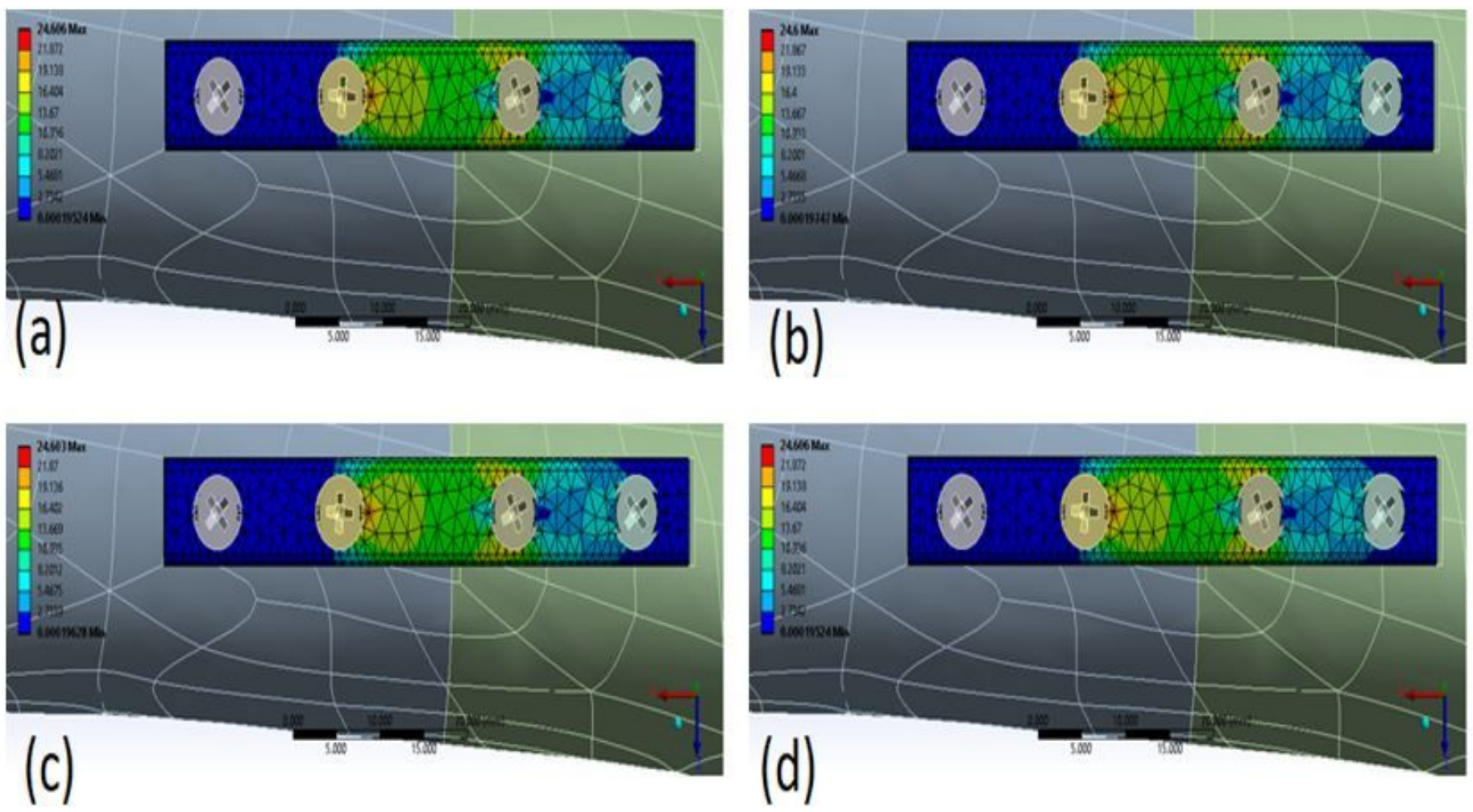

\section{Figure 13}

An equivalent stress under a $100 \mathrm{~N}$ load applied to a compression plate supported on bone (a) S1 sample, (b) S2 sample, (c) S3 sample and (d) S4 sample 

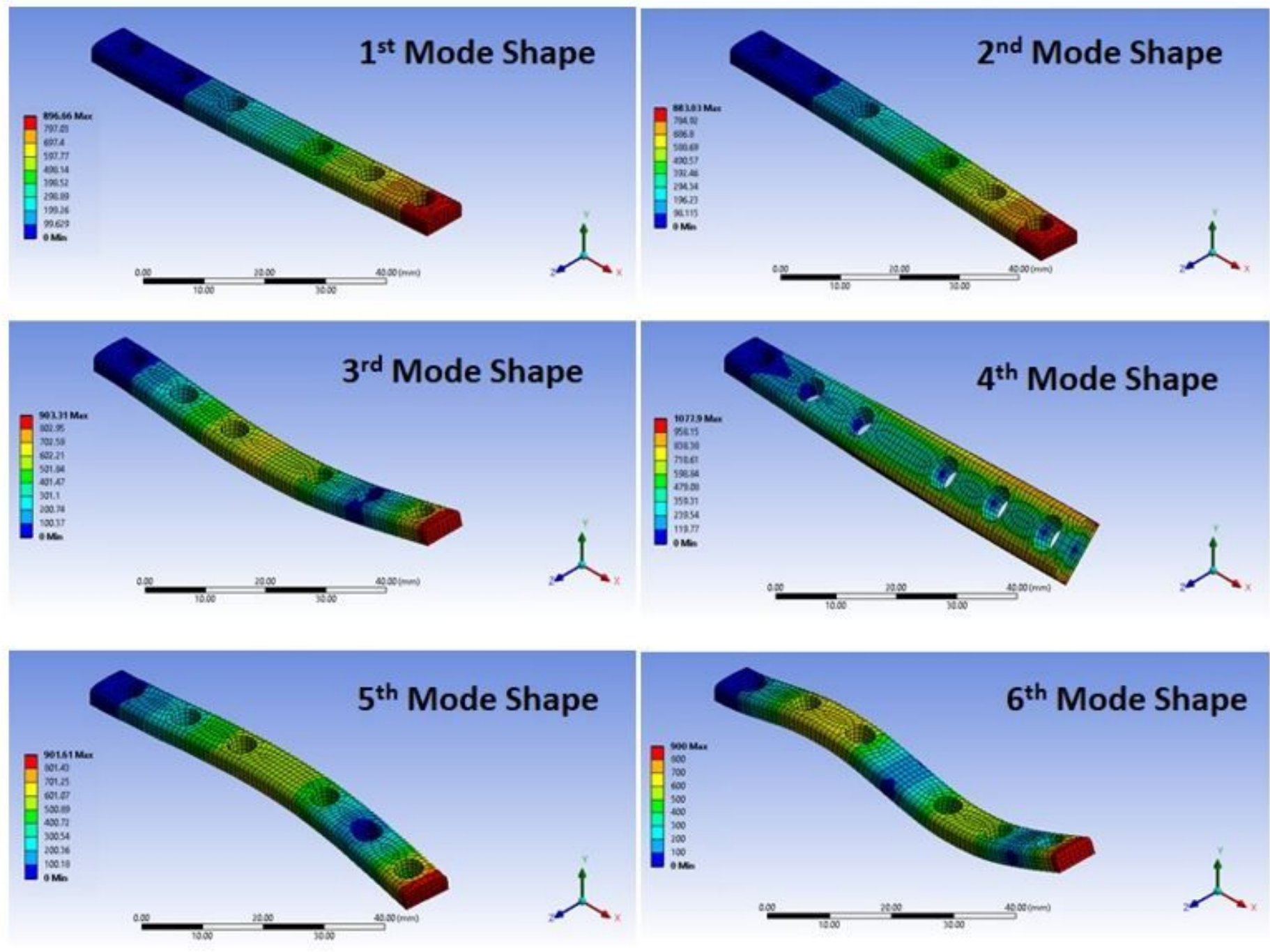

Figure 14

The mode shape of the investigated samples predicted from the modal analysis module 


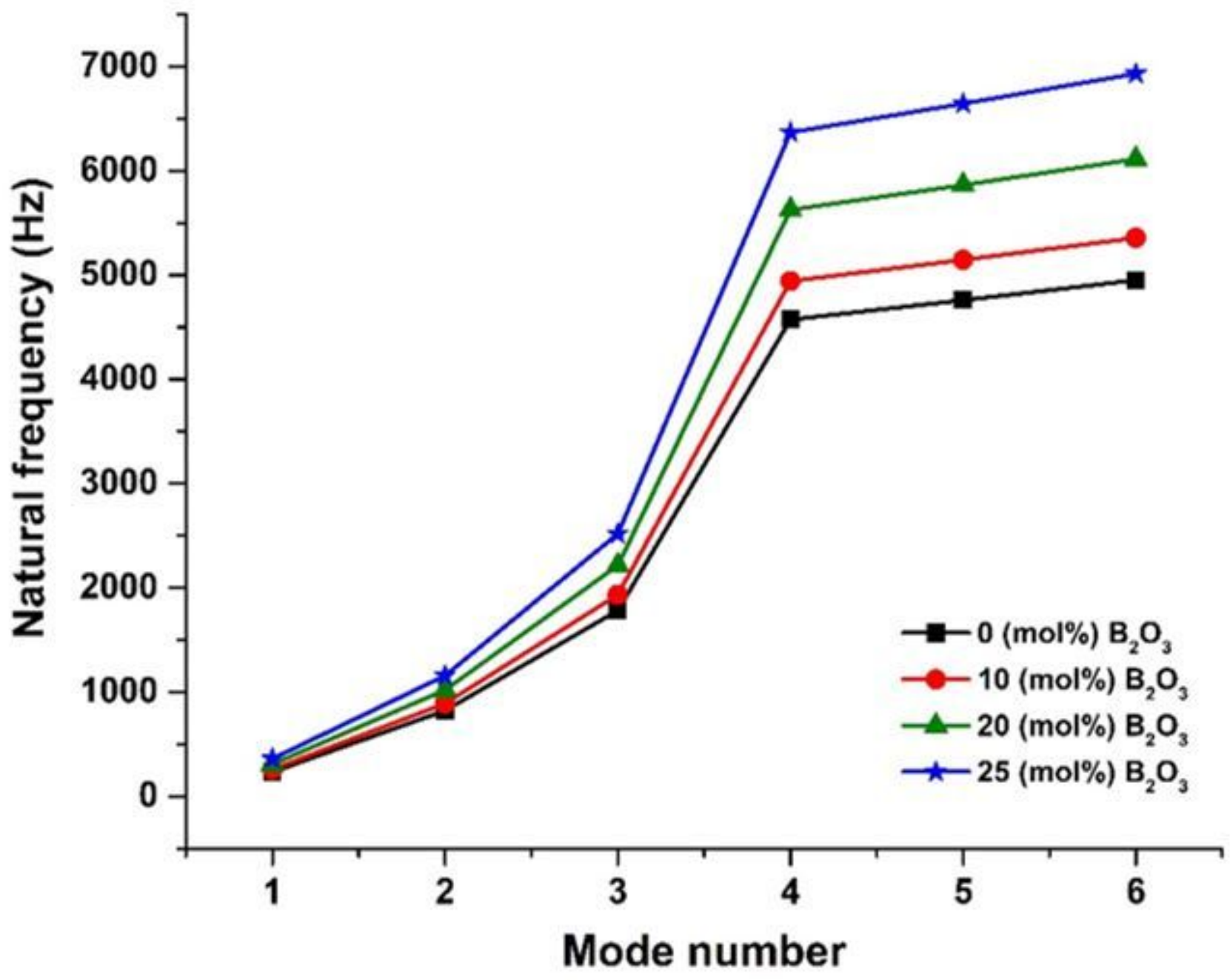

Figure 15

Mode shape and corresponding natural frequency 


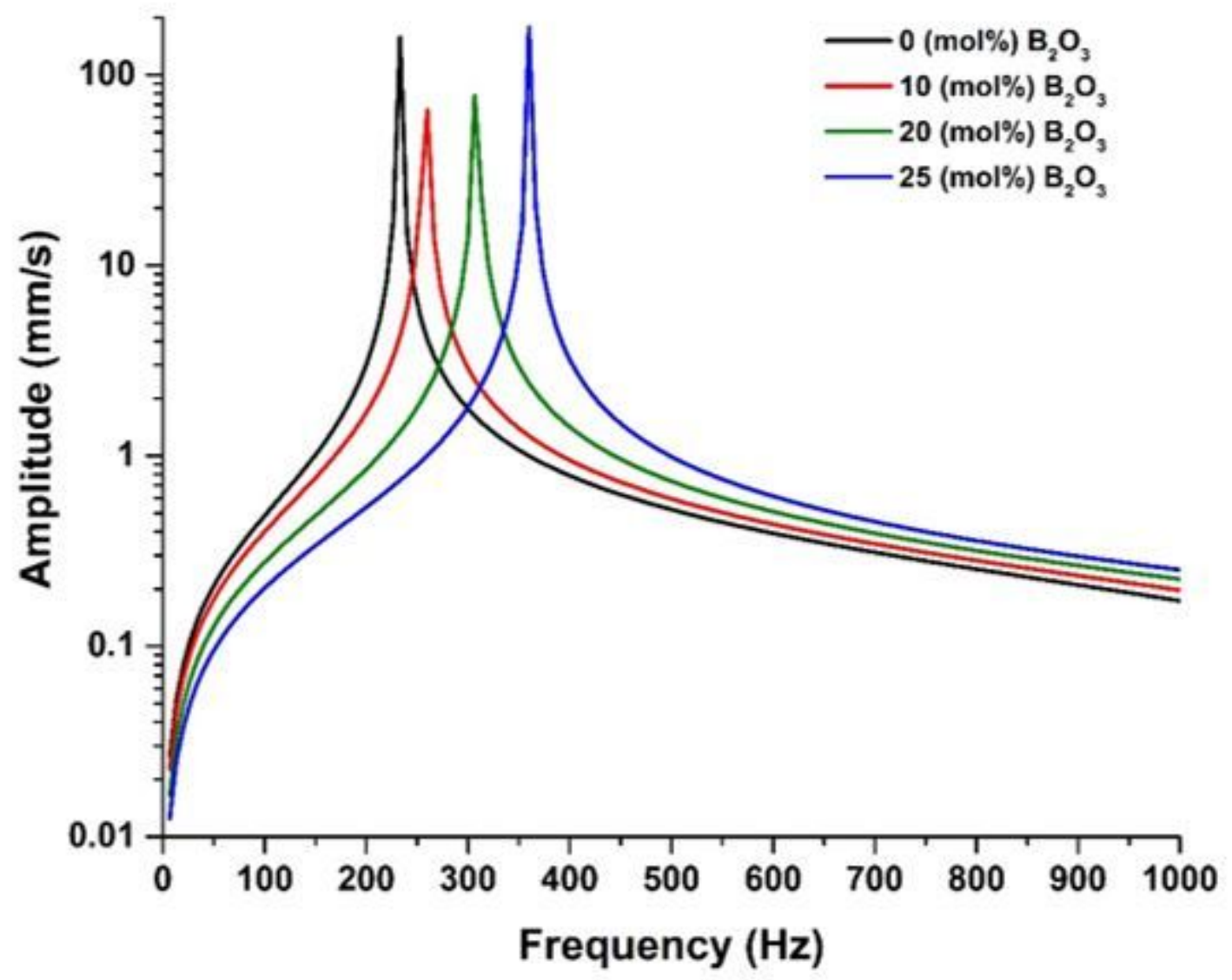

Figure 16

The FRF spectrum of the investigated glass compositions 